\title{
Some Marine Ciliates Living in the Laboratory Tanks at Plymouth, with a description of a New Species, Holophrya coronata.
}

\author{
By
}

W. De Morgan.

With 1 Plate and 32 Figures in the Text.

\section{CONTENTS.}

\begin{tabular}{|c|c|c|c|c|c|c|c|c|c|c|c|}
\hline Holophrya oblonga Maupas & & . & . & : & . & . & . & . & . & . & 601 \\
\hline Holophrya coronata sp. nov. & . & . & . & . & . & - & - & . & . & . & 609 \\
\hline Porpostomum notatum Möbius & & . & . & . & . & . & : & . & . & . & 614 \\
\hline Conchopthirus mytili sp. nov? . & - & . & . & . & . & . & . & . & . & . & 616 \\
\hline Condylostomum patens (O.F.M.) & & . & . & . & . & . & . & . & . & . & 619 \\
\hline Prorodon marinus Möbius & • & . & . & . & . & . & . & - & . & . & 626 \\
\hline Chaenea elongata (Clap. et Lach. & & . & . & . & . & . & . & . & . & . & 629 \\
\hline Spirostomum lanceolatum Gruber & & . & . & . & . & . & . & . & . & . & 631 \\
\hline Frontonia fusca Quenn . & - & . & . & . & . & . & . & . & . & . & 634 \\
\hline Ancistrum mytili (Quenn.) & . & . & . & . & . & . & . & . & . & . & 635 \\
\hline Lionotus fasciola O.F.M. & . & . & . & . & . & $\cdot$ & . & - & - & . & 639 \\
\hline Dysteria armata Huxley & . & . & . & . & . & - & . & . & . & . & 642 \\
\hline Egyria oliva Clap. et Lach. & . & . & . & . & . & . & . & . & . & . & 649 \\
\hline Lacrymaria olor (O.F.M.) & . & . & . & . & . & . & . & . & . & . & 652 \\
\hline Loxophyllum rostratum Cohn & . & . & . & & . & - & . & . & ; & . & 655 \\
\hline Bibliography . . & - & . & . & . & . & . & . & - & . & . & 657 \\
\hline
\end{tabular}

THE Ciliates described in this paper were mostly found living in the tanks at the Plymouth Laboratory, which are supplied with a constant circulation of sea-water from two large storage reservoirs. Most of them 
came from a large shallow tank standing in front of a south window, which is referred to in the paper as "Drake's Island Tank."

\section{Holophrya oblonga (Maupas).}

This ciliate was first found by Maupas (20) on rocks at Algiers among algæ and debris, and described by him as a new species in 1883. I first. noticed it in February, 1916, in Drake's Island Tank of the Plymouth Marine Laboratory, and in July, 1920, many hundreds of large size appeared round the margin of a basin of dredgings from the New Grounds. In 1922 they were found in stuff consisting of algæ, brokendown vegetation, and excreta in dredgings from Asia Shoal, New Grounds, and Millbay. They were very numerous in July and the beginning of August, but gradually diminished, and were scarce at the end of that month. Probably a few individuals might be found in Drake's Island Tank in any month of the year.

Maupas' specimens were of small size, $\cdot 3$ to $\cdot 4 \mathrm{~mm}$. in length. Those found at Plymouth range from about $\cdot 25 \mathrm{~mm}$. to probably $2 \mathrm{~mm}$. in length, and .06 to $.1 \mathrm{~mm}$. in breadth. It is difficult to obtain exact measurements of the animal when alive, and at its maximum extension, but $I$ have measured individuals over $1.5 \mathrm{~mm}$. in length, and fixed specimens of $1 \mathrm{~mm}$. are common. Many of these when alive and extended would certainly reach a length of $2 \mathrm{~mm}$. and probably more, as the animal is very extensile.

The smaller size of Holophrya oblonga (Fig. 1, p. 603), up to about .5 or $6 \mathrm{~mm}$. in length, and occasionally more, found at Plymouth, agrees exactly with Maupas' description. The body is cylindrical, the anterior end symmetrically rounded, the posterior pointed and, in most cases, drawn out into a transparent tail like prolongation ( $\mathrm{t}$ ).

The body is opaque, but not so opaque as it becomes at later stages, and greyish-brown in colour. Maupas calls it greenish yellow. The variation may be accounted for by difference in food.

At the anterior end is a patch of brownish yellow pigment (p), which sometimes forms a collar; and similar pigment occasionally appears at the posterior end. Small patches of it also are distributed through the body.

The endoplasm contains many spherical globules of various sizes, food vacuoles and granules, all of which render the body opaque. Maupas states that when the endoplasm is quite clear and homogeneous, blackish granules may be observed massed at the extremities, and along the axis of the body. I have frequently observed the black granules (bkp) arranged as described; but they are quite visible when the endoplasm is opaque.

The endoplasm is bounded by a fine pellicle marked by exceedingly 
fine striations, only observable under high magnification. Maupas counted ten striæ in a breadth of $\cdot 01 \mathrm{~mm}$. These striations mark the lines of cilia, which are very short, closely packed, and of the same length throughout the body. They are carried on small papillæ slightly raised above the surface of the pellicle.

With increased growth the appearance of the animal changes (Fig. 2). The brown pigment which was collected at the anterior and posterior ends becomes diffused through the body, the number of vacuoles and granules increases, and the whole body becomes very opaque. The taillike end portion disappears, although it occasionally persists to a later period, or the posterior end remains pointed. Generally, however, the posterior end becomes obtuse, and is occasionally wider than the anterior end.

The young animal is active, generally in motion, and swims fairly rapidly, moving the posterior part of the body like a fish's tail and revolving on its long axis. The older and larger individuals are very sluggish, and generally lie inert, slowly protruding and retracting the anterior part of the body. When protruded there is a slight narrowing behind the mouth, giving the appearance of a short neck. Although generally contracted, the animal is capable of great extension, sometimes more than doubling itself. It is also very flexible, and twines about easily among gravel, algæ, etc.

The contractile vacuole $(\mathrm{cv})$ is situated at the posterior end, and is generally spherical in shape. Pulsation is about 60 seconds from diastole to diastole; and at the maximum of diastole, the vacuole fills the whole of the posterior end, being bounded by the pellicle only.

Generally only the terminal vacuole appears; but under certain physiological conditions, at present unknown, and when the animal is contracted, a few well-marked lines may be seen on the body. These are parallel to one another, and slightly oblique to the longitudinal axis of the body. Higher magnification resolves them into a number of very small vesicles, which unite and form narrow canals (C.). When the animal extends itself, these canals lie parallel to the longitudinal axis. I have observed as many as six at the same time, but the number is very variable, generally one to four. They arise from the terminal vacuole and extend to a short distance behind the mouth, where it is possible that they may sometimes unite, although I have never observed them to do so.

At certain points they may enlarge into spherical and ovoid vesicles, and so resemble the rose-wreath pattern described by Daday, and which he took to be the nucleus. They appear in the youngest as well as the oldest individuals. The opacity of the endosare makes them difficult to detect, and Maupas does not appear to have observed them. 


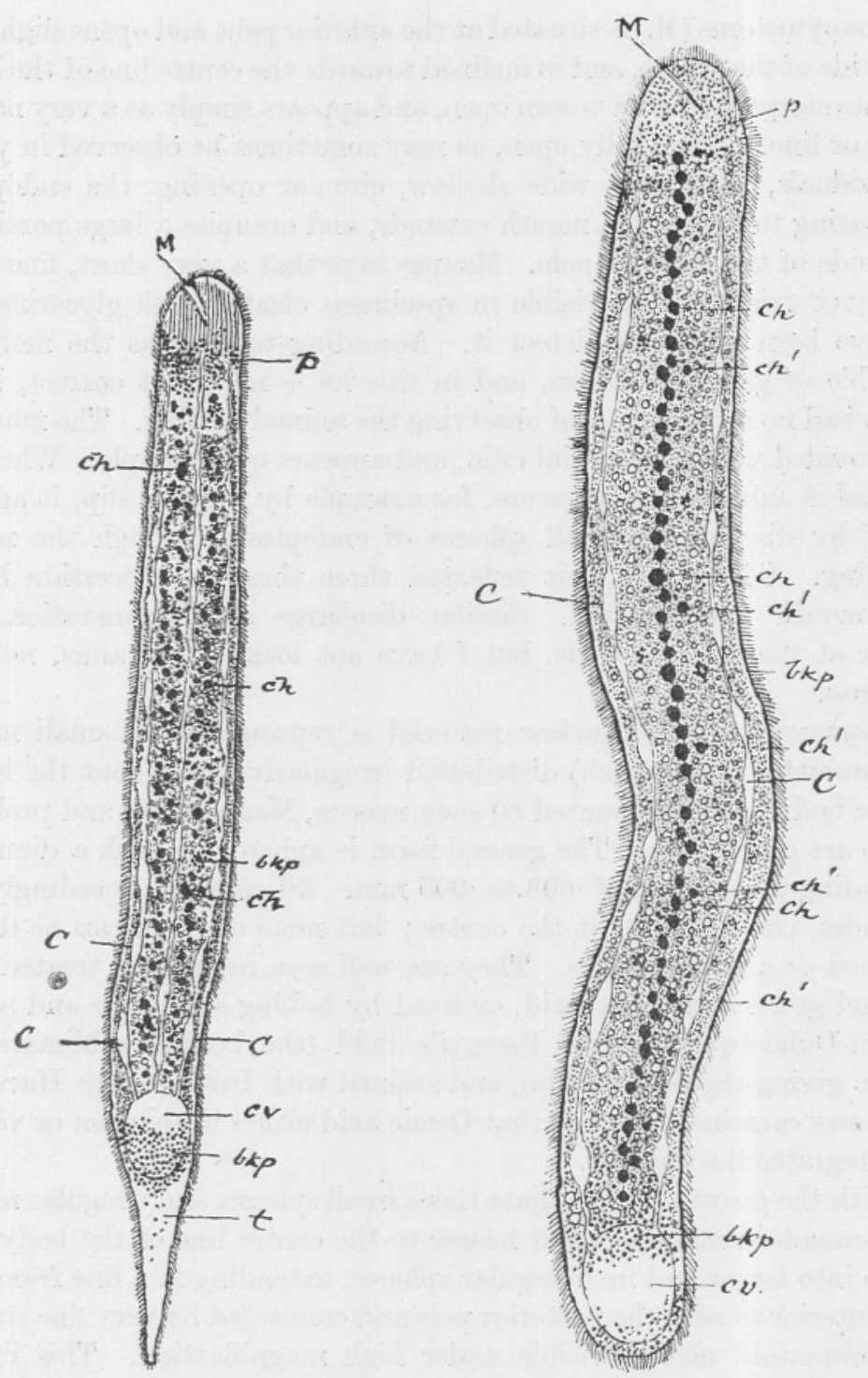

Frg. 1.

FIG. 2.

Fic. 1.-Holophrya oblonga, young form. $\times 118$. M., mouth; cv., contractile vacuole ; $C$., canals connected with contractile vacuole; $c h$., chromatoid masses which later aggregate to form the meganucleus; $p$., brown pigment granules often-forming a collar; $b k p$., black granules; $t$., tail-like extremity.

FIG. 2.-Holophrya oblonga, late form. $\times 118$. M., mouth; $c v$. , contractile vacuole ; C., canals connected with contractile vacuole; ch., chromatoid spheres connected by strands, forming the meganucleus; $c h^{1}$., smaller spheres lying outside the meganucleus ; $p$., brown pigment granules; $b k p$., black granules. 
The cytostome (M.) is situated at the anterior pole, and opens slightly to one side of the centre, and is inclined towards the centre line of the body. In late stages it seldom is seen open, and appears simply as a very narrow cleft or line. When fully open, as may sometimes be observed in young individuals, it forms a wide shallow, circular opening, the endoplasm appearing to rise as the mouth expands, and occupies a large portion of one side of the anterior pole. Maupas says that a very short, fine cytopharynx exists, and is visible in specimens cleared with glycerine, but I have been unable to detect it. According to Maupas the mouth is eapable of great dilatation, and in this he is no doubt correct, but I have had no opportunity of observing the animal feeding. The mouth is unprovided with any special cilia, and appears quite simple. When the animal is subjected to pressure, for example by a cover slip, it adjusts itself by discharging small spheres of endoplasm through the mouth opening. I have seen this repeated three times in succession before the mouth disintegrated. Similar discharge and regeneration may occur at the posterior pole, but I have not located the anus, nor has Maupas.

Meganucleus. The nuclear material is represented by small masses of chromatoid matter (ch) distributed irregularly throughout the length of the body. I have counted 80 such masses, Maupas 100, and probably there are often more. The general form is spheroidal, with a diameter, according to Maupas, of $\cdot 003$ to $.005 \mathrm{~mm}$. All contain exceedingly fine granules, concentrated at the centre; but none of them can be distinguished as a micronucleus. They are well seen in animals treated with methyl green and acetic acid, or fixed by boiling sublimate and acetic, Bouin-Duboseq's fluid, or Perenyi's fluid (the boiling sublimate and acetic giving the best results), and stained with Iron alum or Hæmatin, or Borax carmine. I found that Osmic acid either in solution or vapour disintegrates the animals.

With the growth of the ciliate these small spheres and irregular masses of chromatoid material draw nearer to the centre line of the body, and unite into larger and more regular spheres, extending in a line from near the anterior to near the posterior pole and connected by very fine strands of chromatoid matter visible under high magnificstion. This line of spheres forms the meganucleus. Lying slightly outside the meganucleus are a few smaller spheres $\left(\mathrm{ch}^{1}\right)$. These stain more deeply than the meganuclear spheres, and consist of very minute granules closely packed together. I am unable to detect any connection between them and the meganuclear spheres, and cannot decide whether or not they are to be regarded as micronuciei. There does not appear to be any regularity in their distribution along the line of the meganucleus, nor when division takes place do they divide individually. In one case (Figs. 3 and 4), 
where Holophyra is dividing in two places $\left(\mathrm{H}_{1} \mathrm{H}_{2}\right)$, one of these spheres appears at each end of the dividing ribband. These may or may not be micronuclei, and further observation is required to determine whether their position is not accidental. So far, division appears to be purely amitotic.

Division appears to take place at any period of the animal's life, whether

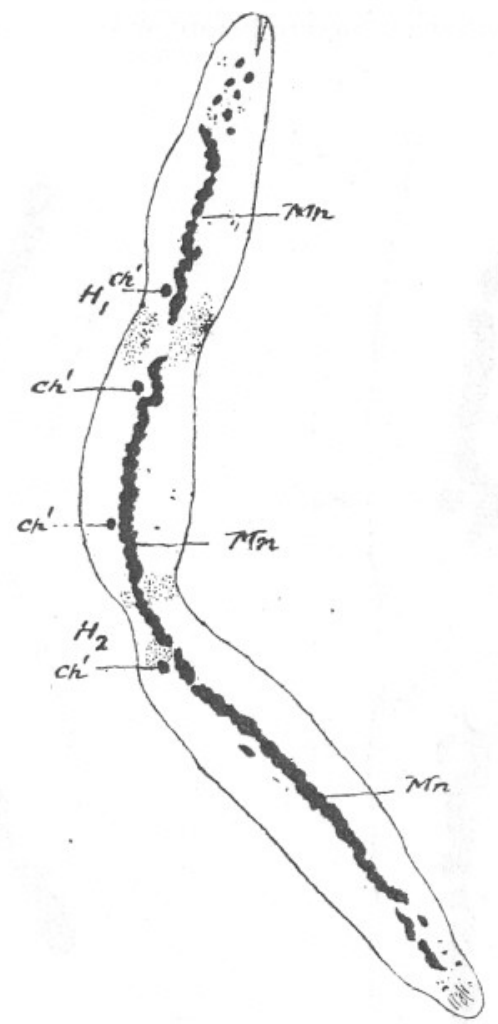

Frg. 3.-Holophrya oblonga. $\times$ 118. Dividing in two places' $\mathrm{H}_{1} \mathrm{H}_{2}$. The spherica masses forming the meganucleus have united to form a ribband $M n$; $c h^{1}$., small spheres lying at ends of dividing ribband.

in the earlier tailed stage, or later, when the line of large spheres has been formed.

Before division the spheres unite to form a ribband (Figs. 3 and 4, Mn), and a constriction appears at the point where separation is to take place. I am unable to discover what controls the position of this point. I have more than once observed division taking place at more than one point, and therefore median division cannot be the rule. I have observed similar multiple division in Dileptus gigas. As 
Holophrya is very sensitive to changes in its environment, I was unable to make successful cultures, and had to rely on any individuals that I met with showing signs of division. Although material was abundant, I obtained but few in this condition.

The constriction deepens slowly, and finally the two portions separate. The contractile vacuole appears at the posterior end of the anterior portion before separation, but I did not observe whether the new mouth was formed in the posterior portion before or after that point was reached.
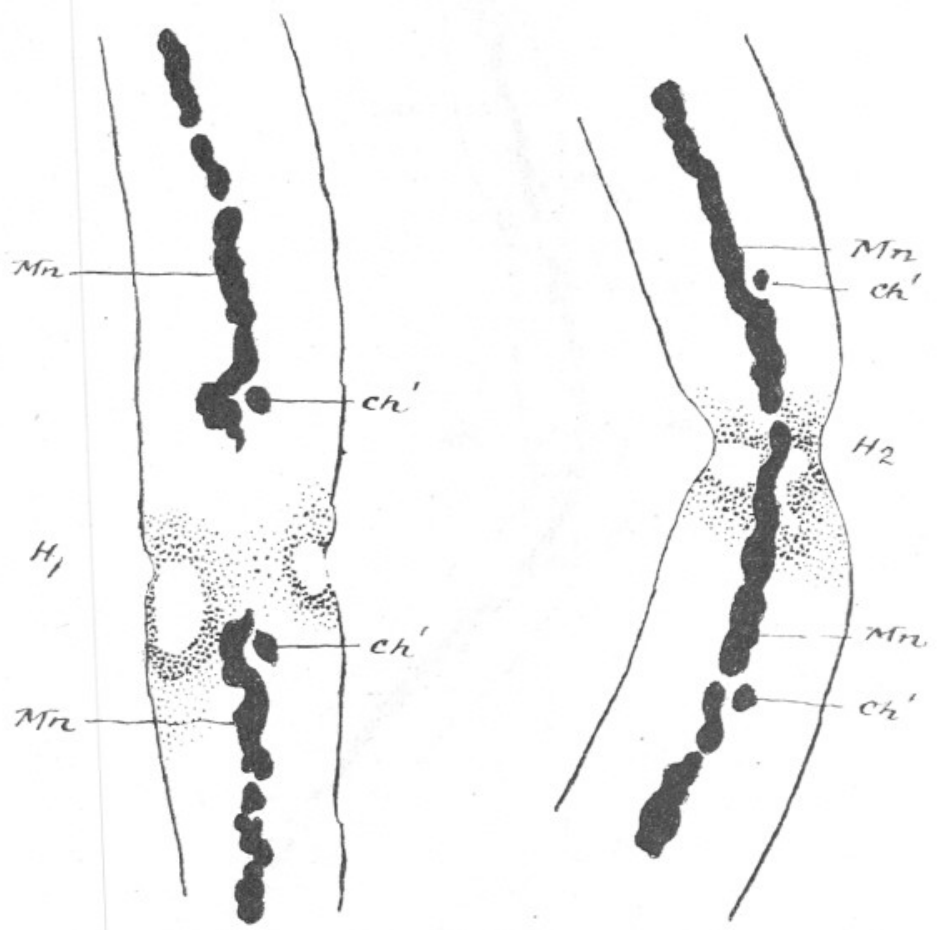

Frg. 4.-The above at points of division. $\times 300$.

The nuclear ribband immediately begins to break up into small spheres and irregular masses (Fig. 5) of chromatoid matter.

Maupas observed division in only one case, but was unable to fix and stain it, and so could not study the nucleus. He only saw a median constriction and formation of the contractile vacuole. He thought it probable from previous observations of the nucleus of Lagynus elongatus, which consists of dispersed masses of chromatoid matter, which remain quite inert during conjugation and division, that the nuclear behaviour of Holophrya oblonga would be similar. My observations of the forma- 
tion of a nuclear ribband previous to division show that this is not the case.

I have never seen this ciliate conjugate or encyst, neither has Maupas.

Maupas placed this infusorian in the genus Holophrya mainly from considerations of its mouth and general organization. He did not consider the length of the body sufficient to justify the separation of H. oblonga from other Holophryans. He also points out that the nucleus in unicellular organisms varies greatly in shape and structure, without affecting the general arrangement of the cell body itself, and that therefore the multiplication of nuclear elements in $H$. oblonga does not afford ground for placing it in a separate genus.

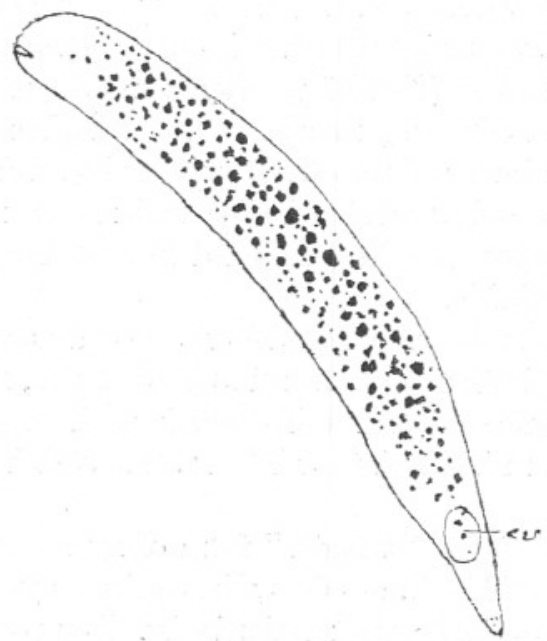

Fig. 5.-Holophrya oblonga, product shortly after division. $\times 260$. The nuclear ribband has already broken up.

In 1886 Daday ( $\boldsymbol{y})$ found in the Bay of Naples, among algæ and bryozoa, a ciliate which he described as a new species under the name of Holophrya maxima. He compared it with Maupas' Holophrya oblonga, which he considered it to resemble in every respect, except :-

(1) Size ; (2) the possession of a tail-like appendage ; (3) the character of the nucleus; (4) ciliation.

(1) Maupas' $H$. oblonga measured $\cdot 3$ to $\cdot 4 \mathrm{~mm}$. in length, Daday's $H$. maxima $\cdot 7$ to $.9 \mathrm{~mm}$., and on account of this superiority in length gave it the specific name. It has already been pointed out that Maupas saw only small specimens of $H$. oblonga, which actually reaches a much greater length than Daday has recorded of $H$. maxima.

(2) The tail-like appendage, which is a drawn-out portion of the 
posterior ectosarc, has been shown above to be generally present in the earlier stages of $H$. oblonga, and occasionally to appear in later and larger individuals. Its occurrence is extremely variable, and it can hardly be regarded as a specific difference.

(3) Daday describes the nucleus as the most interesting peculiarity of the animal, being very different from the nucleus of the genus Holophrya, and reminding him of that of the Stentors. According to him, it consists of a number of masses of nuclear matter connected chainwise. Two of these masses (Pl. I, Fig. $6 \mathrm{~N}_{1} \mathrm{~N}_{2}$ ) just below the anterior end differ from the others in being round instead of oval, one of the two is larger than the other, and they are close together. It differs from that of Stentor, in that it forms a wreath instead of a chain. This nucleus he describes as colourless, and he was unable to find in it either granular masses (Klümpchen) or nuclear bodies (Kernkörperchen); moreover, the presence of many granules and colouring matter in the endoplasm, combined with the fact that the animal is extraordinarily sensitive, and the use of almost all reagents is impossible, rendered observation extremely difficult. It was only accidentally that he succeeded in staining the nucleus and making it faintly visible.

Daday does not state what reagents he used, but as already stated, Holophrya oblonga, both the small and large varieties, fixes readily in all reagents except osmic acid, and stains equally well. Perhaps Daday used osmic acid, but I am inclined to think that his staining was attempted intra vitam.

He also states that the "wreath" form of nucleus was present only in the older forms of his H. maxima; in earlier or younger individuals it consisted of a more or less oval, median body. It appears to me probable that what Daday believed to be the nucleus, was the system of canals connected with the contractile vacuole (see Figs. 1 and 2, C.). A comparison with Daday's Fig. 6 at once shows the resemblance. I have not seen a case in which the canals actually joined anteriorly; but I have seen vesicles connected with the canals below the anterior pole, and the form of the canals is so variable that it is quite possible that the arrangement as drawn by Daday might occur, and also that he missed noticing the connection of the canals with the terminal vacuole.

(4) Daday states that the cilia of $H$. maxima are not scattered, but arranged in eight equally distant rows (Ci) parallel to the longitudinal axis of the body, while those of $H$. oblonga are probably equally distributed over the whole of the body. The cilia of $H$. oblonga are certainly arranged in close parallel rows over all the body, and are very fine and short, but I think that Daday mistook the lines which appear when the canals described in $H$. oblonga are at their minimum diameter for lines bearing 
cilia. Among the number of close-packed striations, it would be difficult to discriminate a line which did not bear cilia, and it required very close observation of many individuals under various conditions to decide that the lines are really particular phases in the formation of the canals.

Moreover, the possession of only eight rows of cilia would be a remarkable variation to occur in the genus Holophrya.

Daday concludes by saying that he does not exclude the possibility that $H$. maxima and $H$. oblonga may be forms of the same species at different stages of development, in which case he would consider the form with a single median nucleus to be the first larval stage, while his H. maxima would represent the fully developed form, and Maupas' $H$. oblonga an intermediate stage.

I have never either in living or fixed and stained specimens seen anything that could be regarded as a median oval nucleus, and I think it probable that Daday may have observed an animal in which the canals had joined together on one side to form a large spherical vacuole, which I have frequently seen to happen. The "wreath" form of canal would then, of course, disappear.

I think, therefore, that it is justifiable to conclude from the above considerations that Maupas' H. oblonga and Daday's H. maxima are one and the same species of Holophrya.

\section{Holophrya coronata SP. NOV.}

I first found this ciliate in 1914 in Drake's Island Tank, and subsequently in dredgings from Asia Shoal, New Ground, and Millbay. It is fairly numerous from May to September, and most abundant in August ; probably a few specimens might be found at any time during the year. In general appearance and habits it closely resembles Holophrya oblonga. with which species it is often found in company, but differs completely from it in the shape of the cytostome and the nucleus.

Resting individuals measure $\cdot 4$ to $.6 \mathrm{~mm}$. in length and $\cdot 06$ to $.08 \mathrm{~mm}$. in breadth. The largest individual I have measured was $1.45 \mathrm{~mm}$. in - length expand d. Like Holophrya oblonga it is very sluggish, generally lying under sand and small pebbles, or among debris of algæ, excreta, etc., and moving its head slowly from side to side. It swims slowly, with an undulating movement, revolving on its axis. The' body is very flexible, and capable of great extension. It is usually cylindrical, but when greatly expanded becomes flat and tape-like, with flattened spaces, alternating sometimes with cylindrical nodes, as is also seen in the case of Trachelocerca phoenicopterus.

The body is very opaque and usually full of food, food vacuoles, granules and small spheres, which are sometimes refringent. The colour 
is a greyish brown, and the anterior portion of the body is generally darker than the rest, possibly due to a concentration of granules, when the animal is contracted. The colour generally is very similar to that of H. oblonga, and occasionally there are a few small scattered masses of yellowish pigment (pg).

The body is surrounded with a very fine pellicle, which shows as a clear margin round the endoplasm. The whole body is covered with fine, short, closely packed cilia, which show as longitudinal striations. Each cilium, as is the case with Holophrya oblonga, stands on a small papilla, but the striations are not so close together as in that species, in which Maupas counted 10 in $.01 \mathrm{~mm}$.; and it does not require so high a magnification to detect them. The cilia are all of the same length.

In resting or slightly expanded individuals the anterior end of the body is rather flattened; it then curves away with slightly diminished diameter for a short distance, which may be regarded as a neck, and then expands again up to the posterior pole, which is very variable in shape, being sometimes larger than the anterior pole, sometimes obtusely rounded, but rarely pointed, and I have never seen an instance of the tail-like termination so general in early forms of Holophrya oblonga. When fully expanded the anterior end forms a regular curve, the margin of the mouth extending very slightly beyond the margin of the body. In Pl. I, Fig. 7 the anterior end of the body represents the fully expanded form, while the remainder is the resting form. When expanded there is little difference in the diameter of the body throughout, except in the neck region which is always slightly narrower.

The contractile vacuole is situated at the posterior pole, generally of

\section{EXPLANATION OF PLATE I.}

FIG. 6.-Holophrya maxima, after Daday. Ci., rows of eilia; $N$., wreath-shaped nucleus; $p$., pigment forming collar at anterior end.

Fig. 7.-Holophrya coronata. Cys., cytostome; Cyp., eytopharynx with supporting rods; $M N$., meganuclear masses: $M i N$., possible micronuclei; pg.,pigment granules ; $c v$., contractile vacuole.

FIG. 13.-Conchopthirus mytili, dividing. References the same as Fig. $12 . \quad \times 260$.

Frg. 20.-Prorodon marinus. MN., meganucleus; MiN., micronuclei ; Cyp., cytopharynx with rods $C i$., lines of cilia and supposed transverse striations; Cry., crystalloid bodies; $C v$., contractile vacuole; $C v v$., vesicles from eontractile vacuole.

FIg. 24.-Frontonia fusca. Ventral view. g., granular mass; MN., meganucleus; MiN., micronucleus; cys., cytostome; psg., peristomial furrow ; $c v$., contractile vacuole. 
Journ Mar. Biol. Assoc. XIII. 3.

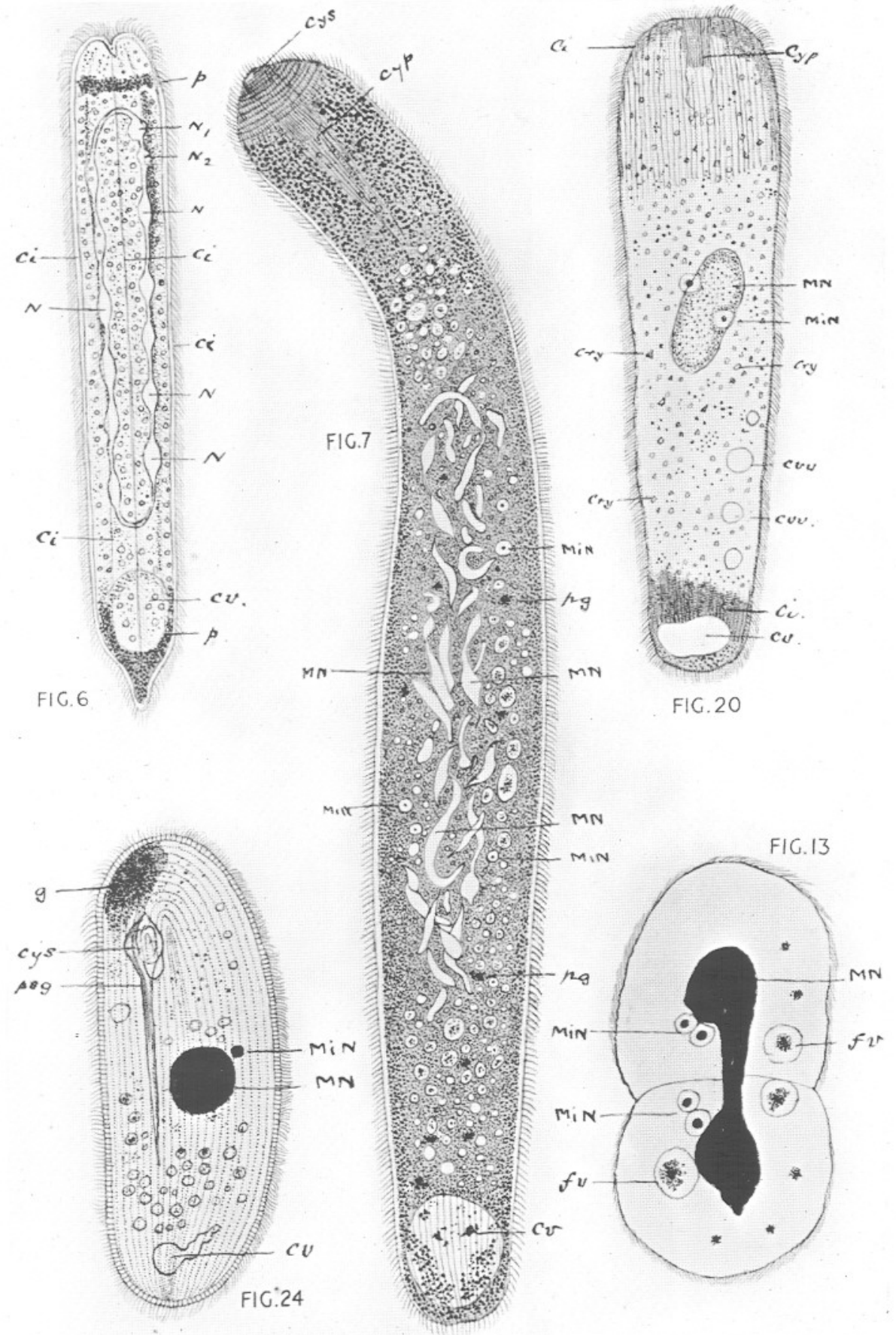

W DE Morgan. Del. 
large size, and sometimes occupies the whole of the body space, being only separated from the exterior by the pellicle. I have never detected any trace of the canal system of vacuoles, so prominent in Holophrya oblonga; but I have occasionally seen the contractile vacuole divided into two nearly equal portions and occupying the opposite angles of the truncated posterior pole.

The cytostome (Cys) (Pl. I, Fig. 7) is situated in the middle of the anterior pole. It is a circular orifice, which leads into a cytopharynx (Cyp), which sometimes extends a considerable distance into the endoplasm. The upper portion of the cytopharynx is provided with a supporting apparatus of very fine rods. The cytostome is surrounded by a series of concentric ciliated circles. I have counted eleven such circles, but the number is probably variable. Each circle carries a row of short closely packed cilia based on small papillæ, and in every respect similar to the cilia disposed longitudinally over the body. It is only when the anterior end is fully protruded that these circles are all visible. When the ciliate is resting, as before stated, the anterior end of the mouth is not extruded, and the surface is flat, consequently only the outer circle and one other is visible. The spaces between the ciliated circles are highly refringent.

The outermost circle surrounding the cytostome sometimes appears studded with very minute clear papillæ. I have never been able to resolve these satisfactorily, but think that they are the result of the cilia "bunching together," as may sometimes be seen in many ciliates.

$H$. coronata feeds principally on diatoms, which often appear in the endoplasm and food vacuoles, and probably also on bacteria, which are frequently found in masses round its body. The cytopharynx is large enough to admit a considerable bulk, but there is no apparatus for capturing prey, nor is the action of the cilia round the cytostome sufficiently powerful to draw in anything except the smallest particles. It is possible that $H$. coronata forces itself over its food as do some ciliates, e.g. Frontonia.

Trichocysts are present, but not in great numbers. They consist of needle-shaped rods, of a maximum length of $.02 \mathrm{~mm}$., and occur mostly at the anterior and posterior poles.

The meganucleus (MN) consists of masses of chromatoid matter, generally spindle-shaped and connected by strands. They are irregularly distributed through the body from just above the contractile vacuole to near the level of the base of the cytopharynx, when the animal is extended; when contracted or after fixation they are concentrated towards the centre. When the body is not too opaque in the live animal they may be seen as clear spaces.

$H$. coronata fixes well with boiling corrosive sublimate and acetic, NEW SERIES.-VOL. XIII. NO. 3. MARCH, 1925. 
Bouin solution or Perenyi's fluid, and stains with Iron Hæmatoxylin, and Borax carmine. Boiling sublimate-acetic and Iron Hæmatoxylin give the best results. Scattered throughout the endoplasm are numerous deeply staining granules, surrounded by a clear space. These may be micronuclei (MiN), but I have so far failed to follow them through division. I have only seen division in two cases, as I have been unable to make successful cultures of this ciliate.

Division, as I have observed it, is rather a slow process. The meganuclear masses unite to form a long flattened ribband (Fig. 8), that

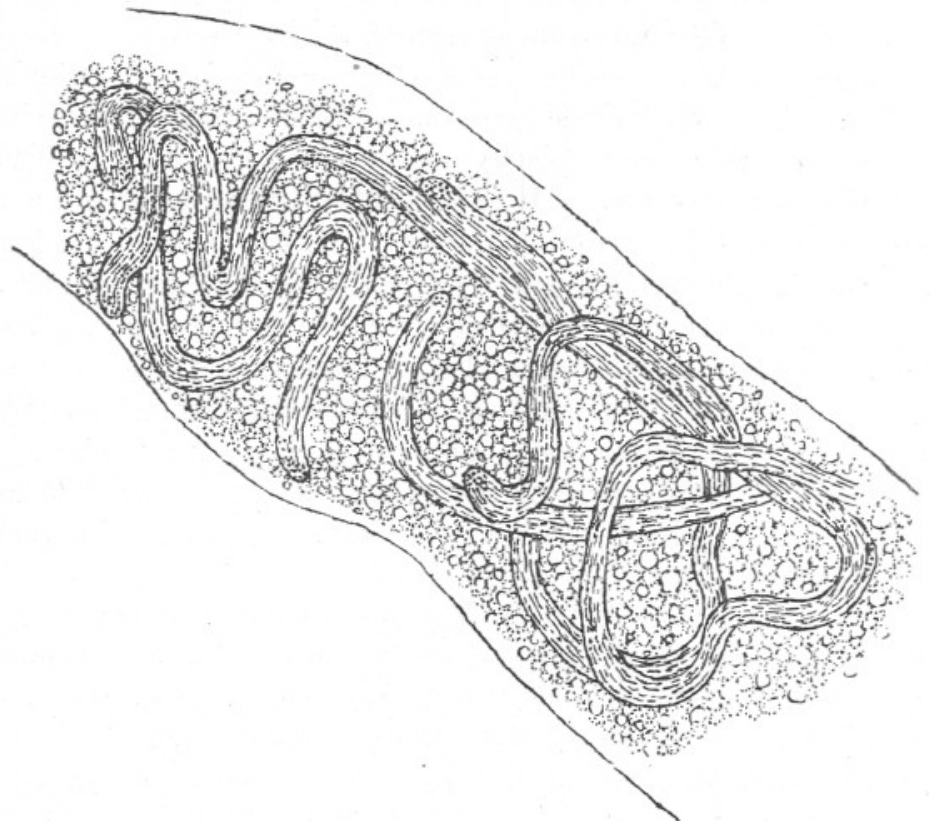

Fig. 8.-Holophrya coronata. Portion of nuclear ribband before division, showing parallel lines of linear chromatoid matter. $\times 300$. Camera lucida. From specimen fixed corrosive acetic, stained Borax carmine.

sometimes passes round and occupies nearly the whole of the interior of the body. It consists of linear portions of chromatoid matter lying nearly parallel to one another, and of various lengths. Under high magnification these may in many cases be resolved into granules.

A constriction in the body then appoars and the two parts finally separate; the ribband immediately breaking up again into irregular masses. While division was in progress I saw no trace of formation of cytostome or cytopharynx, nor of the circles of cilia round the cytostome. The contractile vacuole, however, was formed in the anterior product, as was the case in $H$. oblonga. 
I have observed conjugation in three instances. The animals are in conjunction at the anterior poles (Fig. 9), and a very fine pellicle appears to arise and surround the united surfaces. The nuclear matter consists of spindle-shaped masses, similar in each individual.

I do not know how long the animals had been in conjunction before I found them, and so cannot tell what nuclear transfer, if any, occurred. In another instance I waited until the animals separated, and then fixed them. The nucleus in each consisted of the spindle-shaped masses generally forming the meganucleus.

It is, of course, possible that there may be no transfer of nuclear material during union. (See Minchin, 21, p. 128.)

"In many cases union of distinct individuals can be observed which have nothing to do with syngamy, since no fusion takes place of nuclei,

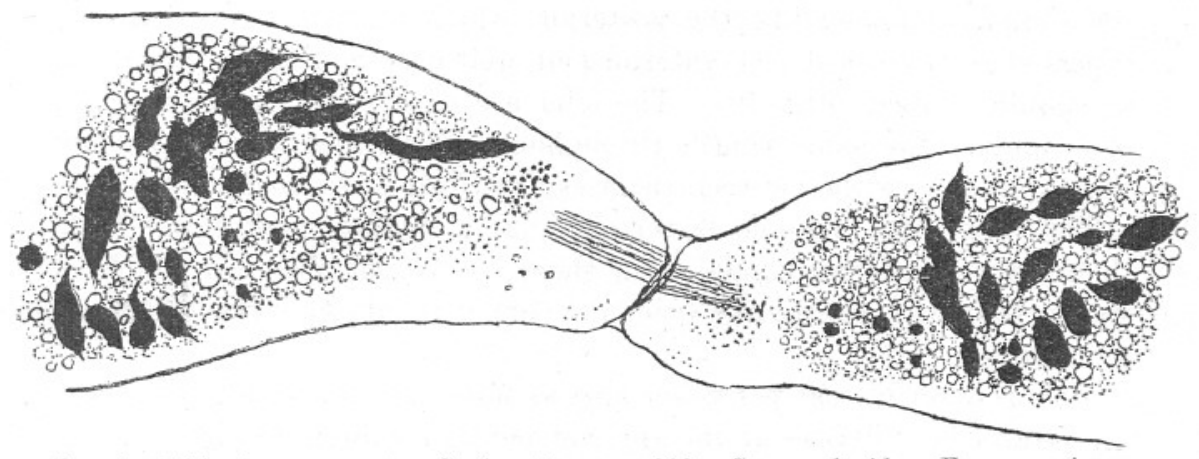

Fic. 9.-Holophrya coronata. Conjugation. $\times 300$. Camera lucida. From specimen fixed corrosive acetic, stained Borax carmine.

but only of cytoplasm. Such unions are distinguished as plasmogamy, or plastogamy from true syngamy. Plasmogamic union may be temporary or permanent; in the latter case it leads to the formation of Plasmodia, as in the Mycetozoa. The significance of plasmogamy is obscure in many cases."

The three cases of conjunction. I observed occurred in the month of September. If they were cases of true syngamy, they might be cases of invigoration previous to encystment (Minchin, p. 140): I do not know whether the animals encyst or not, but they are certainly very rare in winter.

I am unable to find any description of any ciliate resembling this one, excepting Maupas' Holophrya oblonga, and believe that it is hitherto undescribed. The reasons for which Maupas placed $H$. oblonga in the genus Holophrya are certainly valid for the ciliate just described, and I have provisionally called it Holophrya coronata. 


\section{Porpostomum notatum (Möbius).}

Described as a new species from Kiel Harbour by Möbius (22), where he found it among Oscillatoria in February and March. Buddenbrock (2, p. 353) reviewed Möbius' description, from which he differs on certain points, particularly on the structure of the mouth. Buddenbrock obtained his specimens from the Berlin Aquarium.

A few specimens are obtainable from Drake's Island Tank in any month of the year. In 1914 and 1916 they were present in extraordinary quantities in February and March. In 1922 in those months there were comparatively few.

In most particulars my own observations agree with those of Möbius and Buddenbrock. The body is about $\cdot 2 \mathrm{~mm}$. long, and the length about 4 times the breadth. The anterior end is generally pointed, but occasionally rounded like the posterior, which is always rounded. It tapers slightly towards the anterior end, and may be roughly described as spindle shaped (Fig. 10). The cilia are closely set in longitudinal rows and of the same length throughout. High magnifications show close transverse striæ between them as described in Prorodon marinus.

The contractile vacuole is terminal, and Buddenbrock states that there are two afferent canals; but these I have not observed. Möbius states that the contractile vacuole contracts at intervals of 3 or 4 minutes.

Möbius describes the peristome area as somewhat depressed and carrying pectinellæ. It rises at the anterior pole, runs along the left ventral side, and in the middle of the body turns to the right into the cytostome, in which lie two long movable sickle-shaped lips. The gullet is funnelshaped, and bent towards the left side. On the left side near the cytopharynx in the ectosare is a dark speck, slightly concave to the exterior and conical towards the interior. It is surrounded by radially arranged light-refracting rods.

Buddenbrock considers that Möbius is entirely wrong in his observation of this part of Porpostomum, and writes as follows:-

"From the anterior end for about the first third of the body runs a small Peristomefield, gradually widening posteriorly. In its hinder portion it bends slightly towards the left of the mid-line. On the left peristome margin is a pretty thick mane of cilia (Wimpermähne), which probably is composed of pectinellæ, but I have not been able to decide the facts with accuracy. From the peristome, food passes into the S-shaped cytopharynx, of which the commencement, the first curve of the $\mathrm{S}$, forms a pigmented sac. (Möbius speaks of a speck of pigment lying to the left of the cytopharynx.) Actually, the object in question is 
a deep bag, of which the sides and bottom are covered with a dark, finely, granular substance. Under even low magnification this dark mass appears as a dark outline concave anteriorly, and affords a very characteristic mark.

"From the pigmented sac the cytopharynx extends sharply forward to the right, and then turns sharply backwards. The last section is generally

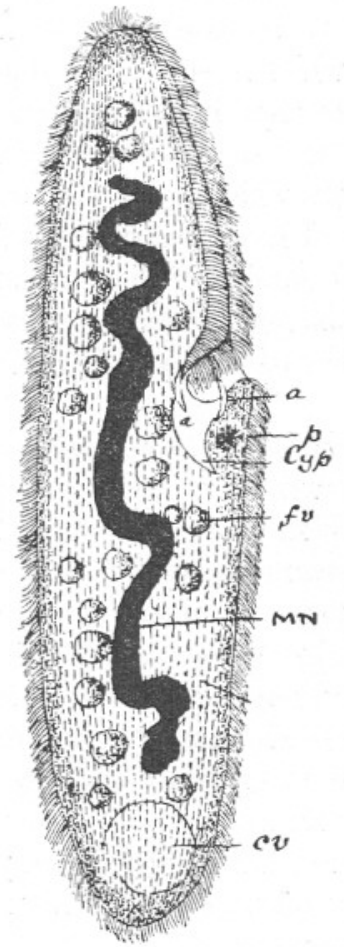

Fig. 10.

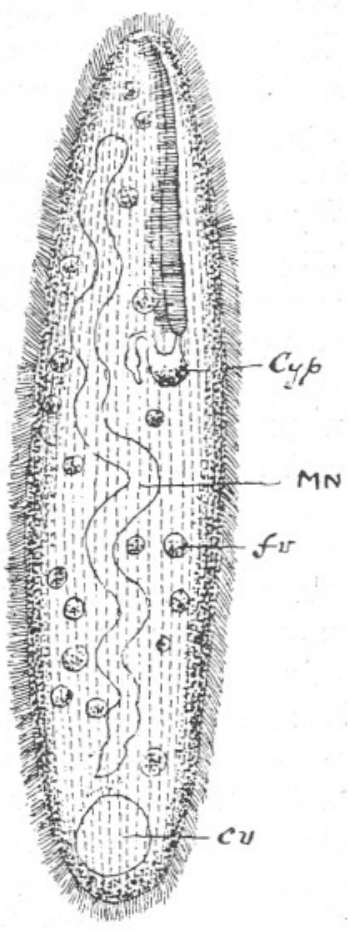

Frg. 11.

Fig. 10.-Porpostomum notatum after Möbius. MN., meganucleus ; Cyp., cytopharynx $a_{1} a_{1}$, sickle-shaped lips ; $p$., pigment speck and sickle-shaped rods ; $f v$., food vacuoles; $c v$. , contrąctile vacuole.

FIG. 11.-Porpostomum notatum, after Buddenbrock. MN., meganucleus ; Cyp., cytopharynx ; $j v$., food vacuole ; $c v$., contractile vacuole.

slightly protuberant. In most cases I found the cytopharynx full of a yellow fluid, which presumably is genetically connected with the pigment. On the significance of either I cannot express a decided opinion.

"To conclude, on whichever side the animal lies, one sees the two curves of the S-shaped cytopharynx in very different positions with reference to one another. 
"The cytopharynx is evidently contractile; it frequently changes its shape under the observer's eye, and occasionally the contained yellow fluid is seen to shift from side to side. Perhaps this motion led. Möbius to the belief that 'two sickle-shaped, movable lips lie in the mouth.'"

My own observations confirm those of Buddenbrock. The general arrangement of the cytopharynx appears to be exactly as he describes it ; but I have not seen the yellowish fluid, which he states that it generally contains. Neither am I prepared to state that it is contractile. The granular pigmented matter contained in the sac is evidently Möbius' pigmented speck lying to the left of the gullet, which he says is surrounded by radially arranged light-refracting rods. I have occasionally observed such rods near the pigmented granules, but outside of the sac ; and such rods are occasionally present in other regions of the body. Occasionally fixed and stained preparations afford a view of the cytopharynx, which bears out Buddenbrock's interpretation.

The meganucleus usually appears as a ribband, lying longitudinally, and sometimes spirally twisted. Before division it generally forms a straight band, and the animal divides by median transverse division. The nuclear matter in the two products assumes a spherical or ribband shape. The nuclear matter sometimes appears as spherical or irregularshaped masses, lying separate or connected by strands, and these become united to form a ribband as the time for division approaches. I have observed four spherical deeply staining masses which may be micronuclei ; but have so far been unable to follow out the nuclear changes leading up to division. Möbius observed division, and that at the time of separation the hinder division product possesses neither mouth, black pigment speck, nor mane of cilia along the peristomial groove. This my own observations both on living and fixed preparations confirm (Fig. 11, p. 615). Möbius further noted the development of the peristomial groove and mane of cilia.

Conjugation I have not observed, nor do Möbius or Buddenbrock refer to it.

The ectoplasm is very clear and contains few granules, but the endoplasm contains many deeply staining food vacuoles.

Porpostomum notatum is but slightly contractile, and undergoes little deformation when fixed. It swims rapidly, with a fish-like movement of the tail.

\section{CONCHOPTHIRUS MYTILI SP. NOV?}

Found in the mantle cavity of the common salt-water mussel. In all my observations I have found it in company with Ancistrum mytiti. 
In shape (Fig. 12) it forms an irregular oval. The dorsal surface is convex, the ventral in the peristomial region, concave. The anterior end is slightly narrower than the posterior, and viewed dorsally the left anterior angle forms a rounded lobe. The thickness is about the same throughout. The posterior margin forms an even curve. Length, $\cdot 15$ to $\cdot 14 \mathrm{~mm}$.; greatest breadth, $\cdot 08$ to $.11 \mathrm{~mm}$. About midway on the ventral margin a deep groove commences, leading to a fossa in the anterior third of the body. This is the eytopharynx (Cyp) which reaches to a depth of rather less than $\frac{1}{3}$ of the body width. The depth of the cytopharynx appears constant, and I have never observed any extension of it further into the endoplasm. It is lined with long cilia. When a sufficient quantity of food, such as small algæ, etc., is collected at the

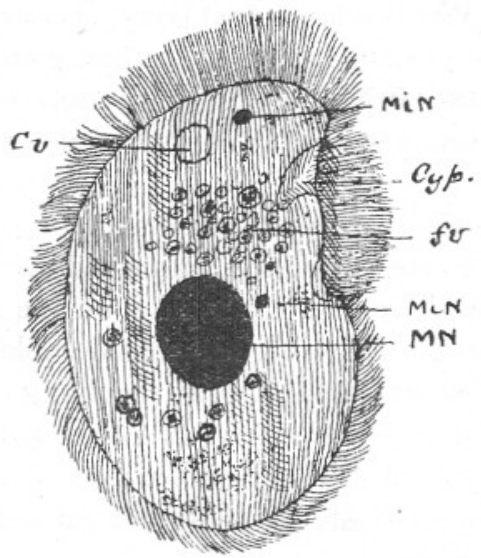

Fig. 12.-Conchopthirus mytili. MN., meganucleus; MiN., micronucleus; Cyp., cytopharynx; fv., food vacuole; $c v$., contractile vacuole. $\times 260$.

base of the cytopharynx, these cilia may be seen beating in slow, regular strokes, and so pressing the food against the base of the cytopharynx, until the ectoplasm is ruptured, and the food disappears within the endoplasm.

The body is surrounded with a thick pellicle, as is often the case among parasitic ciliates. Under the action of methyl green and acetic the pellicle expands away from the cytoplasm of the body, and is seen to be covered with close set striations, which mark the position of the fairly long, fine cilia with which the body is covered. Along the right margin of the peristomial groove is a row of very closely set, fine, long cilia. When at rest, and under a low power, these appear like an undulating membrane. This, under a high power, is resolved into its component cilia. By these cilia food particles are swept into the cytopharynx, and thence pressed into the cytoplasm, as noticed above. The cilia at 
the anterior end are much longer than those covering the rest of the body; nearly as long, in fact, as those along the peristomial margin. When the animal is at rest, the anterior cilia lie erect and rigid, while those along the posterior margin continue in rapid motion. This recalls the behaviour of Ancistrum mytili under similar circumstances. There are numerous food vacuoles, sometimes collected at the base of the cytopharynx, sometimes arranged round the nucleus, sometimes completely filling the posterior half of the body.

The contractile vacuole is at the anterior end; I have never seen it in any other position. It is spherical in shape and occasionally breaks up into a few smaller spheres, but I have never seen any canal formation. It functions at a varying rate : from forty to sixty seconds between diastole and systole.

The meganucleus (MN) is a large oval body, occupying a nearly central position. It is visible as a clear space in the living animal. There appear to be two micronuclei (MiN). Division is transverse. Each product of the division contains a spherical meganucleus and two micronuclei. (See Pl. I, Fig. 13.)

There do not appear to be any trichocysts.

Conchopthirus is persistent in shape, possessing hardly any contractility or elasticity. It moves about fairly rapidly on the surface on which it is resting, and by means of its cilia has considerable power of cohesion. It occasionally takes short, jerky flights, revolving on its axis.

Engelmann (11) describes two species of Conchopthirus, C. curtus and C. anodonta, both found in the fresh-water mussel Anodon. They both resemble the Conchopthirus of the salt-water mussel in many respects, but differ in certain points.

In $C$. curtus the cytopharynx is long, recurved and tubular. The contractile vacuole lies below the nucleus, and is stelliform or rosetteshaped. In both these points $C$. curtus differs essentially from C. mytili, but resembles it in having an oval meganucleus, with two micronuclei.

In Conchopthirus anodontce the oval fossa occupies the centre of the body, while the cytopharynx curves inward, and nearly reaches the posterior extremity. The contractile vacuole is subcentral, and the meganucleus posterior.

It also differs from C. mytili in shape, being longer in proportion to the breadth.

Both the above species, according to Engelmann, have, on the ventral surface of the posterior end, a row of about six larger and stronger cilia. These do not appear in C. mytili.

Conchopthirus Streenstrapii Stein, found in the body slime of Succinea amphitia, and of many land snails, differs from C. mytili, in having the contractile vacuole subcentral, and a nucleus consisting of seven cor- 
puscles lying parallel to the posterior and right lateral border. The matting of the cilia is a character common to all the genus.

\section{Condylostomum patens (O. F. Müller).}

Condylostomum patens is a very widely distributed form of ciliate, and the following are the principal articles dealing with it. As Trichoda patens, O. F. Müller (23); Kondylostoma limacina, Bory (1); Uroleptus (?) patens, Ehrenberg, Alhandl. der Berliner Acad. von 1833, s. 278 ; Kondylostoma patens, Dujardin (8); Kondylostoma patens and K. patula, Claparède and Lachmann (5); Condylostoma patens, Stein (26); Fresenius (13) ; Cohn (6); Quennerstedt (25); Rees; Levander (19); Maupas, 1883 (20) ; Gourret and Rœsor, 1886 (15); Calkins (4); Wrzesniowsky (28); Schewiakoff (27).

The descriptions of Stein and Maupas are the best and most detailed I have read.

This species appears to be mainly pelagic. The fresh-water species of the genus, C. vorticella, tardum, and sphagni, as described by Penard, differ considerably, especially in form. The Condylostoma vorticella, which approaches nearest to $C$. patens, is much shorter and more rounded.

Condylostoma patens (Fig. 14) is very common, and widely distributed. In Drake's Island Tank it is present nearly all the year round, and I have found it very abundant in February and May. The form is pretty constant, and although there are slight variations, the animal is very conspicuous and easy to recognize.

In colour those in Drake's Island Tank are greyish with a slight yellow tinge; occasionally they may be almost colourless, and specimens which I have seen from rather brackish water were distinctly yellowish.

Maupas gives the length as $\cdot 305$ to $\cdot 495 \mathrm{~mm}$.; Stein, $\cdot 376$ to $\cdot 564 \mathrm{~mm}$. ; and Calkins, $\cdot 4 \mathrm{~mm}$. length, and $\cdot 1 \mathrm{~mm}$. breadth at widest part. Thus, generally speaking, Stein's specimens were longer and narrower than those of Maupas, who says that he never saw the length more than 5 times the greatest breadth, while Stein gives the length as seven or eight times the breadth.

I have found that no definite limits can be fixed to length and breadth. In a single sample from Drake's Island Tank individuals of all the lengths mentioned by Stein and Maupas may be found. It appears to be simply a question of growth and feeding. The same may be said of the shape of the body. Stein says that it is nearly cylindrical, Maupas that it is flattened ventrally and dorsally, and Claparède and Lachmann also speak of the dorsal and ventral flattening. Calkins calls the general form elongate and cylindrical, and somewhat smaller anteriorly. I have very 
seldom found anything resembling this description, or the figure he gives, among the Drake's Island Tank individuals. Generally the dorsal

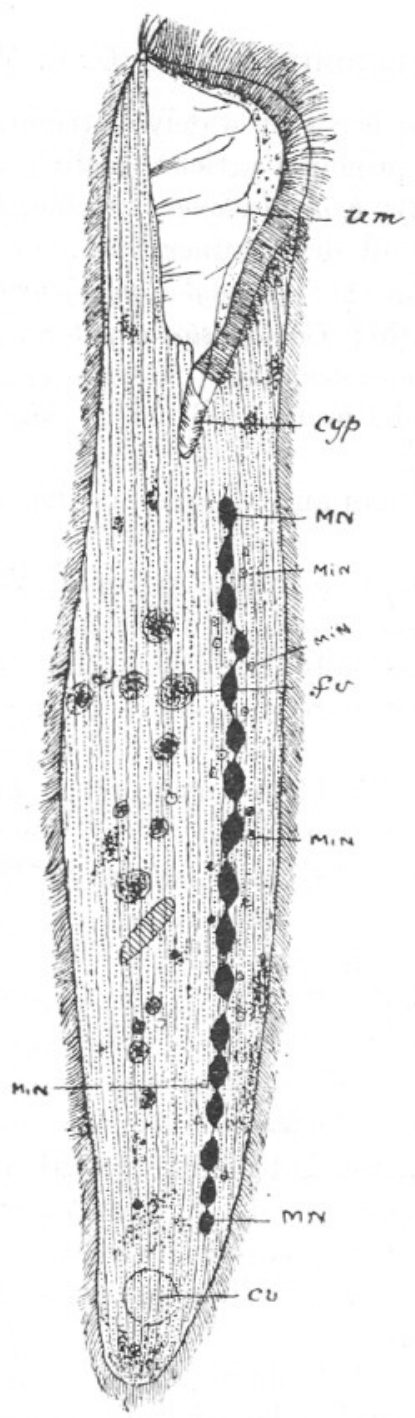

FIG. 14.-Condylostoma patens, MN., meganucleus; MiN., micronuclei ; um., undulating membrane ; Cyp., cytopharynx ; $c v$. , contractile vacuole ; fv., food vacuole.

surface is considerably arched and flattens out gradually in the posterior third of the body. The ventral surface is flattened. The anterior end rather narrower than the median breadth, and the posterior gradually tapered. This is the shape when the animal is fairly quiescent. When 
it is swimming about it elongates, and assumes shapes resembling those described by Stein and Maupas. As stated before, the appearance as described by Calkins is rare. There is generally a slight decrease in width just beyond the lower angle of the peristome, and in cases of great extension this is materially increased, accompanied by flattening of the anterior portion, sufficient to produce a spoon-like appearance.

The peristome is large and triangular, and catches the eye at first sight of the animal. The base of the peristomial triangle forms nearly the whole of the anterior margin of the body. Stein says that it occupies $\frac{1}{5}$ or $\frac{1}{6}$ of the body length, Calkin $\frac{1}{4}$ or less. It depends on the state of the animal at the time of measurement; but in any case $\frac{1}{4}$ of the body length is a high estimate. The right edge of the peristome bears a welldefined undulating membrane, to which Maupas does not directly allude. Gourret and Rœer (15) describe it as a fine hyaline membrane (membranella), which carries along its whole length a kind of velum. This is smaller than the membranella, and produces a vigorous vortex by its flapping. In the Plymouth specimens I have failed to distinguish the membranella and velum - although the undulating membrane, which is situated as Stein (26) describes, is a very conspicuous object.

In the inferior angle of the peristomial area is the mouth which leads into the gullet. Stein describes the gullet as long and serpentine, while to Maupas it appears not much longer than broad. Gourret and Rœser describe it as a quadrilateral pocket, of which the opposite angles have an opening ; one of these openings, which is continuous with the posterior extremity of the peristome, forms the cytostome, while the other leads into the body of the animal.

From observations of Plymouth specimens I could not assign a fixed definite shape to the cytopharynx. It appears as a shorter or longer continuation of the peristomial area, of varying width. Stein, Maupas, and Gourret and Rœerer all agree that it is ciliated ; but Stein is doubtful whether the cilia visible are only continuations of the adoral cilia or whether the whole inner surface of the cytopharynx is ciliated. The presence of the cilia on the surface of the body make this a difficult point to decide; but I am inclined to think that they cover all the interior surface of the cytopharynx. Maupas states that the cilia hollow out a digestive vacuole in the sarcode; on the arrival of food the vacuole fills, detaches itself, and gradually passes down the body, until the contents are discharged outside. Gourret and Rœeser state that a hyaline vacuole is usually ready, and that as soon as it is filled another takes its place. This seems to me to be what takes place, except what is stated by Gourret and Rœser in regard to the new vacuole taking the place of the detached one. It depends on whether more food is arriving. 
The right anterior angle of the anterior margin forms a curved projection, which Stein says is characteristic. The left margin forms a regular curve. The left inner margin of the peristome carries a row of closepacked, well-developed cilia, which terminate on the right anterior projection, in four or five cirrhi. The cilia of the anterior margin are the longest, and gradually decrease in length down to the level of the mouth. The whole of the body is covered with short fine cilia arranged on moderately spaced, slightly oblique striæ. The dorsal and ventral body cilia are of the same length; but at the posterior extremity they appear to be slightly longer, and often anchor the animal by attachment to foreign matter. The peristomial area has no cilia, and is so transparent that the striæ and ciliation of the dorsal surface are visible through it.

The above describes the ciliation of the Plymouth variety. The animal described by Maupas differs considerably in ciliation. According to that observer, the dorsal cilia are fine, very closely set, and in a state of perpetual vibration. The ventral cilia are coarser and further apart, and do not vibrate continually, but move slowly, in obedience to the will of the animal, and are true ambulatory cirrhi, similar to those of Euplotes and the Oxytrichids. When Condylostoma is resting they are quite motionless.

Morphologically, he concludes, that they are true cilia, but functionally ambulatory cirrhi. The four or five cirrhi on the right anterior angle Maupas considers absolutely identical with the cirrhi of Euplotes and the Oxytrichids, and sees in them indications of the law by which the heterotrichous type of ciliate is transferred into the hypotrichous. There are also on the dorsal surface, but only easily observable on the margins of the body, tufts of fine silky bristles. These Maupas considers homologous with the bristles observable on the dorsal surface of all Hypotrichous Infusoria.

Again, Maupas describes the appendages of the adoral zone, not as stout cilia, but as membranellæ similar to those of the Oxytrichids. There is also a clear laminar boundary which carries the frontal membranella, and which he considers homologous with the Oxytrichid overlip. In the above points Maupas' Condylostoma, of which he gives excellent figures, differs considerably from the Plymouth specimens, and those described by Gourret and Rœeser, Calkins, and Stein.

Contractile vacuole. In the Plymouth variety I have never seen a regularly functioning contractile vacuole. A large posterior, irregularly shaped, apparently empty space, is often present. The size and shape vary considerably among individuals ; but I have never observed diastole and systole, and this is also Maupas' experience. On the other hand, Stein describes a regular water canal system, of a very active nature. 
Stein places the anus at the posterior extremity of the body. Maupas declares that he has frequently observed the anus functioning; that it opens on the dorsal surface near the right margin and about the level of the last and middle third of the body, and in its position he sees another point of affinity between Condylostoma and the Hypotrichid Infusoria. $\mathrm{He}$ accuses Stein of being frequently inexact in describing the position of the anus of ciliates. In certain cases the observations of Gourret and Rœeser confirm Maupas. In others the anus appeared near the posterior end and on the left margin of the body. Again discharge of fæcal matter was observed through two orifices on the left side, and after discharge no orifice could be recognized. Gourret and Rœser are sure that the anus is formed by rupture of the cuticle, and that after expulsion of the fæces the edges of the temporary orifice coalesce.

I have never been able to make out a permanent anal opening. Fæcal matter appears to escape at any point where pressure overcomes the resistance of the cuticle, and, immediately after, the surface is regenerated.

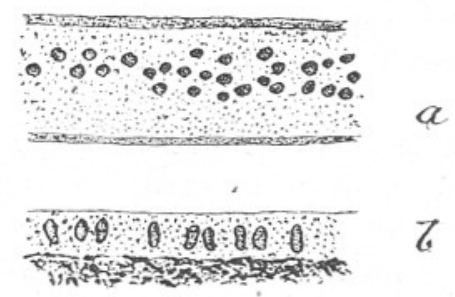

FIG. 15.-Condylostoma patens. Surface view $(a)$ and section $(b)$ of Integument. $\times 1280$. (After Maupas.)

Maupas describes the striations of cilia as slightly oblique to the longitudinal axis of the body from right to left, and as being not so numerous as generally represented. The striæ on the Plymouth variety agree in being slightly oblique, but they are not spaced so widely as Maupas shows them. He describes them as consisting of homogeneous fibrillæ,. bounding wide granular bands. At the base of the granular substance are refringent corpuscles or rods, which are not trichocysts, and form in his opinion the principal elastic element of the integument (Fig. 15). Gourret and Rœser, on the other hand, hold that the fibrillæ are only the result of cuticular thickening, and, though undoubtedly elastic, should not be considered as the principal element of elasticity. The intermediate bands they regard only as body sarcode and nutritive vesicles. From microscopic examination of the living animal and stained preparations it is difficult to come to any definite decision, which probably will only be arrived at by microdissection.

The meganucleus (MN) is moniliform. The component masses of 
nuclear matter, according to Stein and Maupas, are connected by strands of chromatoid matter. This is evident in numerous preparations I have made. Gourret and Rœerer, however, state that the "nodosities" of the meganucleus, as they term them, are generally separate; but that sometimes they are closely connected in the anterior part of the body.

Neither Stein nor Gourret and Rœeser observed the micronuclei (MiN). In stained preparations a number of opaque central corpuscles, surrounded by a clear space, may be seen. They measure about $.002 \mathrm{~mm}$. in diameter, and the clear space about $.005 \mathrm{~mm}$. Maupas believes these to be the micronuclei. The number varies in different individuals, and does not correspond with the number of meganuclear " beads," being sometimes greater and sometimes less. Maupas found 17, 15, 14, 14, 16, 15 " beads" with 14, 15, 14, 13, 18, 18 nucleoli respectively. Their distribution among the meganuclear beads is quite irregular.

They may be compared with the small dark stained corpuscles lying beside the meganuclear spheres in Holophrya oblonga; their appearance and behaviour is generally constant, but in certain phases of division is not quite clear.

In Division the meganucleus commences by contracting into a homogeneous central mass. At this stage there is no constriction of the body, but a rudimentary peristome commences to develop on the ventral surface. Shortly afterwards constriction commences, accompanied by an enlargement of the new peristome.

The meganucleus lengthens to form a more or less sinuous ribband, and the micronuclei (Fig. 16) are drawn along the margins in company with it, finally concentrating at the two poles (Fig. 17). Maupas states that the condensation of the meganucleus is probably preceded by a micronucleolar division, for he frequently observed a number of micronuclei collected at either pole of the meganuclear mass. I have not observed such a marked polar concentration of micronuclei at this phase as Maupas described. In one case a number of micronuclei collected together, and forming a sphere, which stained less darkly than the meganucleus, were seen collected at one pole where single micronuclei appeared to be absent; a large light-staining sphere appeared containing what resembled micronuclei. It appears to me possible that there is a stage at which the micronuclei aggregate together to form a single spherical mass of chromatoid matter, which divides and separates into single micronuclei. This point requires further investigation. It may be noted that the micronuclei are exceedingly small, and that Iron Hæmatoxylin might give better results than Paracarmine with which my specimens were stained. 
The constriction then deepens, and the new peristome is completed. The ribband-like meganucleus commences to divide at the level of the body constriction. Finally the two halves separate. Figs. 18 and 19 (p. 626) show two cases of division products. In both the meganuclear ribband is beginning to constrict, and in one has resumed the monili-

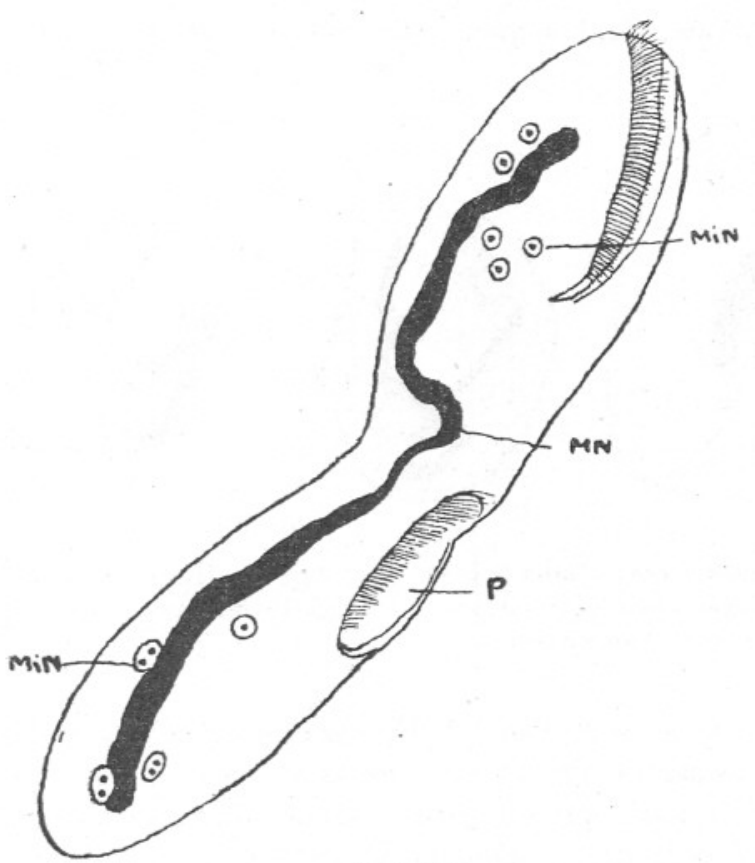

FIG. 16.

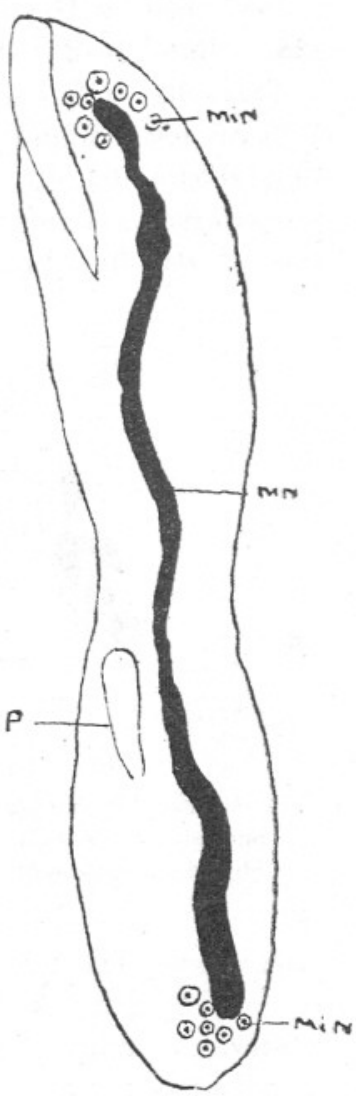

FIG. 17.

Frg. 16.-Condylostoma patens, dividing. Micronuclei on ribband, MiN. ; MN., meganucleus; $P$., new peristome. $\times 300$.

Fic. 17.-Condylostoma patens, dividing. Micronuclei concentrated at poles. References as above. $\times 300$. Camera lucida.

form state. It is to be remarked that in both, which are at the same stage, i.e. immediately after division, the condition is very different. In one the micronuclei (Fig. 18) are numerous and separate. In the other I was unable to detect any. In the latter case, however, the animal was full of food-vacuoles and granular matter, which made detection difficult. 
Condylostoma patens is very hardy. It will live in stagnant water, and will stand long journeys.

\section{Prorodon marinus (Möbius).}

Described by Möbius (22); Claparède and Lachmann (5); Quennerstedt (25) ; Bütschli (3); Kent (18).

This ciliate (Pl. I, Fig. 20) is not common in Drake's Island Tank, and I have never found it in abundance like Holophrya, Porpostomum, Condylostomum, etc. The body is cylindrical, rounded anteriorly and posteriorly as a rule; but occasionally the anterior pole is prolonged into a teat-like projection, and occasionally the posterior pole is

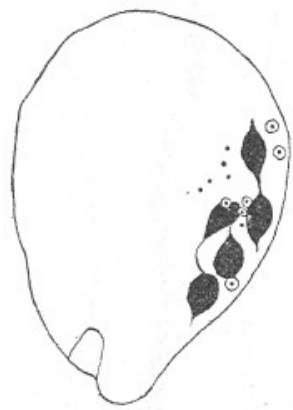

FIG. 18.

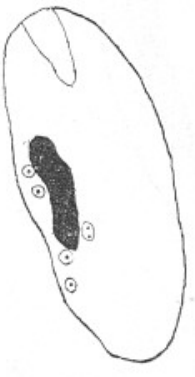

18.
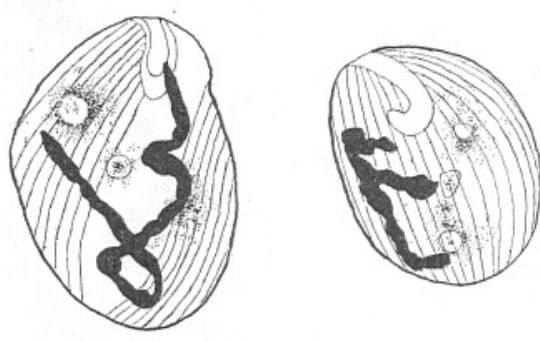

FIG. 19

FIGS. 18 AND 19.-Condylostoma patens, after division. In Fig. 18 many micronuclei and in one product meganucleus is moniliform. In Fig. 19 micronuclei absent. Slightly compressed. $\times 300$. Camera lucida.

truncated. The whole body is covered with close rows of fine cilia of equal length. Möbius states that in some cases he noticed a longer posterior cilium. This I have not observed. Each cilium stands on a spike-like papilla. This is very noticeable in marginal views of the animal. Möbius states that the layer of endosarc under the pellicle is very finely cross-striated. This appears to me doubtful. Under high magnification striæ are certainly visible; but one end of every striation is wider than the other, and I think that the striations are really the cilia pressed down by the cover slip, and consequently occupying a position transverse to two neighbouring rows of cilia. No transverse striæ are visible when the animal is moving freely. It is possible that the cross-striations observable in some other ciliates, e.g. Trachelocera phonicopterus, and Porpostomum notatum, are due to this cause.

Möbius gives the length of the ciliate as $\cdot 19$ to $\cdot 22 \mathrm{~mm}$., and breadth $.08 \mathrm{~mm}$. Plymouth specimens are much larger. The largest fixed speci- 
men I have measured was $\cdot 45 \mathrm{~mm}$., and lengths of $\cdot 32, \cdot 30, \cdot 28 \mathrm{~mm}$. are common.

Along with the cylindrical individuals, there are often found smaller ones which are quite spherical. In all other respects but this they are similar to the cylindrical Prorodons. The drawing of Claparède and Lachmann resembles one of these. Möbius thinks that the drawing was from one of the cylindrical ones under pressure from the cover slip. I am inclined to think that it is simply an early stage of the same animal.

Roughly speaking, the length may be stated as varying from twice to three and a half times the breadth.

Below the layer of cross-striated (Möbius) endosare is another containing strongly light-reflecting crystalloids. These give a very glassy transparent appearance to the animal. They are not destroyed by fixing. There are frequently numbers of dark granules in the endosare, and Claparède and Lachmann state that the animal is sometimes so full of refringent granules as to appear almost black.

The contractile vacuole is situated in the aboral pole. Möbius states that it is never spherical, but often lengthened obliquely. Like other contractile vacuoles it is very variable in shape, I have often seen it spherical. It often divides into many smaller vacuoles. Diastole and systole are slow. Claparède and Lachmann describe it as a large posterior vacuole filled with a fluid containing rod-like corpuscles, which might be taken for trichocysts, but are possibly the remains of a digested infusorian.

Cytostome anterior in the middle of the oral pole. Quennerstedt's figure shows it slightly to one side. Circular when open and very contractile. Sometimes situated on a teat-like prolongation. The cytopharynx is funnel-shaped, and has a basket-like arrangement of rods about forty in number. It can be so closely contracted as to be hardly visible. The cytopharynx appears to be ciliated, but the animal is so transparent as to make it difficult not to confuse the ectodermal cilia.

The meganucleus is spherical or egg-shaped, generally situated in the middle of the body, but sometimes more anterior or posterior. It is visible in the living animal and stains readily with all ordinary stains ; but Möbius states that his specimens would not respond to carmine or indigo.

There are generally two micronuclei, in most cases close to the meganucleus.

I have never seen the animal divide, nor is the process described in any of the authors I have consulted. Möbius, however, frequently observed encystment. The animal assumes a spherical shape. The cilia beat slowly and at last cease entirely, and lie sloping on one another, 
forming a border round the body. Then a very thin colourless cyst is secreted. In some cysts two individuals were found, probably, he thinks, arising from division of one mother individual.

Möbius saw many individuals assume the spherical form after resting sometime in the cyst, and leave it without dividing. During the rest the contractile vacuole functioned very slowly. The encysted individuals often had a deep transverse fold, resembling a division furrow. He appears not to have noted any nuclear changes, or what took place while the animal was in the cyst.

Prorodon marinus swims slowly, revolving on the long axis, sometimes with the anterior, sometimes with the posterior pole in advance. It is not very contractile in any direction, nor does it alter much in size by fixation.

Buddenbrock (2) describes a new species which he found in the Berlin Aquarium, as Prorodon binucleatus.

The principal difference of this animal from $P$. marinus is the possession of two nuclei lying very close to one another. In fact, Buddenbrock thinks that it would be better described as a two-limbed, than a spherical nucleus. The body is about three and a half times as long as broad. Wider anteriorly than posteriorly. In starving animals the posterior end is sometimes flattened. Extremely contractile and can assume a spherical shape. Cilia in many longitudinal rows. Very flexible. Ectoplasm separates very distinctly from the apparently quick flowing endoplasm. Cytostome terminal, funnel-shaped, and so delicate that its minute structure could not be investigated. It lies embedded in a plug of ectoplasm, which at this point is evidently more strongly developed than in the rest of the body, and can be protruded like a nipple (as was noticed in P. marinus). Contractile vacuole nearly or quite terminal.

The colouring is characteristic. An anterior and a distinctly separate posterior portion are separated from one another by the almost glassclear zone containing the nuclei. The anterior section is always filled with many granules that strongly refract light, and under low powers appears almost black. The posterior section behind the nucleus may be very transparent with only a few central granules. Sometimes individuals are met with in which large granules make the posterior part of the body appear darker than the anterior. Nucleus generally transverse. Rarely do the two spheres lie one above the other.

Swims moderately swiftly, revolving on the long axis. The cilia of the anterior one-third of the body may be seen moving extremely swiftly, the remainder playing an unimportant part in the movement.

I have inserted this description, as the differences between $P$. marinus and $P$. binucleatus are so small, that the latter may prove to be only a variety of the former species. 
Chaenea elongata (Clap. et Lach.).

Has been described by different authors under the following names: Chaenea teres Gourret and Rœser (15) ; Enchelyodon elongatus Claparède and Lachmann (5); Lagynus elongatus Maupas (20); Chaenea teres Kent (18); Chaenea vorax Quennerstedt (25).

The genus Chænea was formed by Quennerstedt to include a form resembling Enchelys farcimen of Ehrenburg, and Enchelyodon elongatus of Claparède and Lachmann and Trachelius teres of Dujardin. Quenner-
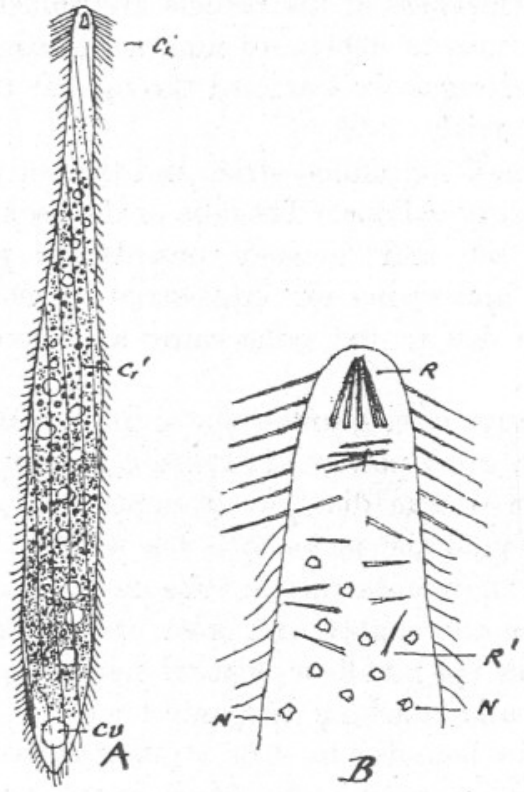

Frg. 21.-Chaenea elongata. A. Ci., stout posteriorly directed cilia; $c i^{1}$., oblique rows of body cilia ; $c v$., contractile vacuole. The small dark dots are nuclear matter. B. Anterior part. $\times 630$. $R$., apical rods ; $R^{1}$, rods scattered through the body. $N$., small masses of nuclear matter.

stedt gave it the specific name of vorax, on account of its predatory habits. Maupas, however, considers that it has nothing in common with the genus Enchelyodon, and replaces it in the genus Lagynus, founded by Quennerstedt in 1867. Whatever may be its position in the scale of classification, there is no doubt that the ciliate described by Maupas is identical with that found in fair numbers in Drake's Island Tank, as follows :-

In form this ciliate (Fig. 21) is a long spindle. The length varying 
from $\cdot 070$ to $\cdot 225 \mathrm{~mm}$. The proportion of breadth to length is very variable -from an average of 1 to 5 , to as much as 1 to 8 , or even 10 . The body narrows from the anterior to the posterior end; but there is always a distinctly marked short anterior portion, which may be called the neck, and which forms a very variable portion of the total length. The posterior end is obtuse, and capable of considerable distention. There is a contractile vacuole at this end, and I have seen it functioning - I have seen one or two vacuoles in other parts of the body, but not pulsating. They were, however, not food vacuoles. The body is rather opaque, with many food vacuoles and refringent granules.

Throughout the thickness of the pellicle are numerous pointed rods, which Maupas measures at .006 to $.01 \mathrm{~mm}$. in length, and $.001 \mathrm{~mm}$. in breadth. They are irregularly scattered throughout the body. Maupas believes them to be trichocysts.

There are very fine longitudinal striæ, and the body cilia follow their lines, which are slightly oblique. The cilia of the neck are rather longer, stouter and closer set, and directed towards the posterior. I have not observed the appearance of cross-striation noted by Maupas; possibly it may be due to the same cause as described for Prorodon marinus.

The mouth is always closed, unless the animal is swallowing its prey, and then it displays great powers of extension. Maupas relates that he has seen a Chænea of $\cdot 01 \mathrm{~mm}$. diameter attempting to swallow a Uronema of $028 \mathrm{~mm}$., but found the morsel too big for it. Only Maupas has correctly described the mouth region. The neck region is fairly translucent, and may be thoroughly examined under high power. Under $\frac{1}{6} \mathrm{in}$. there appear in the middle a clear triangular space with the apex pointing to, and nearly touching, the anterior end. Under $\frac{x}{12}$ in. this space is shown to be bounded by 4 or 5 (Maupas says 2 or 3 , but the number varies) needle-pointed bodies of about the same size and structure as those in the body, called by Maupas trichocysts. Lying irregularly scattered at the base of these are a few other bodies of the same nature, irregularly disposed.

I have examined many individuals and in all have found these rods forming an apical isosceles triangle; and it is these evidently which Claparède and Lachmann mistook for the rods, which are often found in the cytopharynx of ciliates.

Maupas describes how the long cilia around the neck form eddies which suck in small animalcules, which are then paralysed by the trichocysts, and swallowed by the Chænea.

It is remarkable that acetic acid does not cause a discharge of the trichocysts in Chænea, as is usually the case with other ciliates.

Claparède and Lachmann describe the nucleus as an oval disc ; Gourret. 
and Rœser did not see one, nor could Quennerstedt detect one by pressure or staining. Maupas, by fixing with osmic or acetic acid, staining with picrocarmine and clearing with acetic acid and glycerine, found small nuclear masses, of varying size and number, distributed in all parts of the body, the number varying in proportion to the size. In some cases eight to ten nuclear masses of about $.005 \mathrm{~mm}$. diameter, in some as many as 100 , measuring not more than $.0015 \mathrm{~mm}$. diameter.

Using picro-formal-acetic and paracarmine, and methyl green and acetic on the live animal, I got similar results. With animals in process of division, I did not find any change in the nuclear arrangement, neither did Maupas. He also observed Chænea in conjugation with a similar negative result.

The presence of a nucleolus has not been demonstrated. I found Chænea in water containing putrifying matter, to the presence of which it does not appear to object, but it is very sensitive to change in the concentration of the sea water.

\section{Spirostomum lanceolatum (Gruber).}

This ciliate was described by Gruber (14) as a new species of Spirostomum from the harbour of Genoa. It is fairly abundant at all times of the year in Drake's Island Tank, except in January, February and March, when only solitary specimens are obtainable. It generally lies inert on the bottom among algæ and fine gravel, but when in motion is capable of considerable extension, with flattening and folding of the body.

The general form (Fig. 22, p. 632) is that of a lancet or long spindle, the widest part being about $\frac{1}{3}$ of the body length from the anterior end. From this point it tapers away gradually to a fine posterior point. The length of the body is about $\cdot 3$ to $\cdot 35 \mathrm{~mm}$. when resting, but when extended in swimming reaches $\cdot 45$ or $\cdot 5 \mathrm{~mm}$. The breadth is about $\cdot 041$ to $\cdot 045 \mathrm{~mm}$. Gruber gives the length as about $\cdot 2 \mathrm{~mm}$., and this is the only point in which his specimens differ from those found at Plymouth. The anterior end of the body is wider than the posterior, and when the animal is lying with the mouth uppermost, has a slight angle projecting to the right. The peristomial area does not extend much beyond the anterior third of the body. Viewed ventrally the cytostome is seen to lie slightly to the right of the centre line of the body. From the cytostome the peristomial groove extends to the right towards the anterior end, so forming an arc of a spiral, which is very noticeable, and characteristic of the genus Spirostomum. The right margin of the peristomial groove carries a row of cilia longer and stouter than those which cover the body, and which combined with their spiral course make it easy to recognize the 
animal. There is a short, rounded cytopharynx, into which, according to Stein (26), in describing Spirostomum teres, a very similar species, these peristomial cilia are continued. The motion of the surface cilia makes observation difficult, but I am disposed to agree with Stein. Claparède

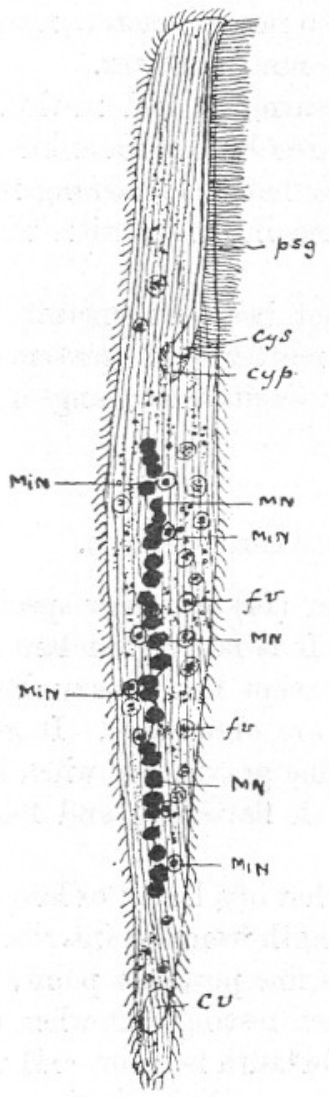

FIG. 22,

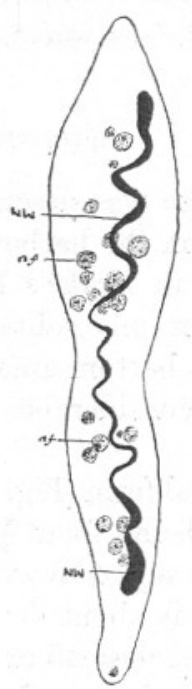

Frg. 23.

FrG. 22.-Spirostomum lanceolatum. MN., meganucleus ; MiN., possible micronuclei ; psg., peristomal groove ; cys., cytostome ; cyp., cytopharynx ; $f v$., food vacuoles ; $c v .$, possible contractile vacuole.

FIG. 23.-Spirostomum lanceolatum, dividing. MN., meganuclear ribband; fv., food vacuoles.

and Lachmann, in describing $S$. teres, think that the cytopharynx contains a single cilium, or a bunch of cilia. This is improbable.

There is no undulating membrane. The body is covered with rows of striæ; which carry very fine cilia. The minute structure of these striæ in Spirostomum teres has been described by Stein. 
In underfed individuals the meganucleus may be seen as a number of clear spheroidal masses, very similar to those described in Condylostomum patens (Fig. 22). They lie in a row parallel to the longitudinal axis of the body, and are variable in number. Gruber, in describing his fixed and stained preparations, says that the peculiarity of the component of the meganucleus is that they are dumb-bell shaped, just as if they were in a stage of division; but that this condition cannot be considered as a transitory one, as he found it repeated in all the preparations he examined.

'In his drawing, all the elements of the meganucleus are not dumb-bell shaped, there being two solitary spheres. Of these he remarks that they may either be the result of a break up of a dumb-bell-shaped mass, or that they are in course towards union to form the dumb-bell.

In my preparations I find dumb-bell-shaped masses, spheres, and aggregates of spheres. Single spheres are more numerous, and generally there are connecting strands of chromatoid matter. It seems probable that the natural form of the meganucleus is a number of spherical or ovoid masses connected by strands of chromatoid matter, as in Condylostoma patens, and that the dumb-bells and aggregates of spheres are stages on the way to the collection of the nuclear matter into a single mass, previous to the formation of a ribband, and subsequent division. Fig. 23 shows Spirostomum lanceolatum about to divide.

The single meganuclear masses consist of a number of very small spheres, similar to those described and figured by Stein (Pl. II, Fig. 12.) in Spirostomum teres.

Lying beside the meganuclear masses are a number of small spheres similar to those described in Condylostoma patens, as possible micronuclei. They are sometimes, but not invariably, surrounded by a clear space.

They are about the same size as the spheres of which the meganuclear elements consist. I have not been able to trace them through division, but I could not find them in the case where the ribband was formed (Fig. 23). I have seen cases where the small sphere appeared to be extruded from the meganuclear element. Gruber does not mention the micronucleus. I have not seen any case of conjugation.

Gruber says nothing of the contractile vacuole. I have occasionally seen a posterior vacuole, but have never observed it pulsating. Possibly, like some other marine ciliates, Spirostomum lanceolatum does not possess one.

Stein describes, as Spirostomum teres, a ciliate which in many points resembles the Spirostomum found at Plymouth; but differs in having a more obtuse posterior end, with an oval, kidney spindle, or horseshoeshaped nucleus, and an actively functioning contractile vacuole, with a system of canals, similar to those in Holophrya. Stein examined a speci- 
men from the Baltic, but the majority of his observations were on freshwater forms, which may account for the variations.

\section{Frontonia fusca (Quenn.).}

Frontonia fusca (Pl. I, Fig. 24) differs considerably from the freshwater Frontonia leucas, described by Schewiakoff (2y). Frontonia leucas is wider at the anterior than at the posterior end, while $F$. fusca is about the same width throughout, with equally rounded ends. In $F$. leucas the peristomial furrow extends about $\frac{2}{3}$ of the body, while that of "fusca" reaches at times quite to the posterior end. In this it resembles the marine form of Frontonia leucas as described by Calkins (4). The arrangement of the contractile vacuoles in $F$. fusca also is very variable.

In Fabre-Domergue's figure, reproduced in the Nord-Plankton, XIII, p. 51, two are represented, one in the anterior and the other in the posterior third of the body. In the Plymouth form I have only observed one, at the posterior end. This sometimes breaks up into smaller spheres, which may unite to form a sort of short canal, or may form a canal leading a little way from the large sphere. I have never observed any system of radiating canals as seen in the fresh-water species.

Calkins, in describing his marine Frontonia leucas, notes that in the Woods Hole specimens they are very irregular in size, and very much branched, but not uniform or radiating, as in Schewiakoff's description.

Frontonia fusca differs from both Calkins' marine and the fresh-water Frontonia leucas, by the presence of a large mass of granules on the left anterior margin of the body (the ventral side being uppermost). This appears almost black, but in the Plymouth specimens is really a deep green. Similar granules to those composing it are scattered all over the body also and are light green in colour. This spot does not appear in Calkins' marine Frontonia nor in the fresh-water species.

The mouth of Frontonia fusca, as far as I can see, resembles that of Frontonia leucas, which has been minutely described by Schewiakoff; and also by Maupas (20), under the name Ophryoglena magna. These two observers differ in their interpretation of the arrangement of the deeper parts of the oval fossa, and of the peristomial furrow. Schewiakoff's description appears to me to be correct, though I cannot detect the rows of cilia in the furrow, which sometimes extends to the posterior end. As Schewiakoff says, these cilia are shorter than the body cilia, and so closely placed together that they "als ob sie auf einer Leister stiinden." It is, in fact, difficult to say whether they are lines of cilia or simply lines. 
I can only detect one undulating membrane. There is not much difference between Frontonia leucas and Frontonia fusca in size. The individuals I have measured of $F$. fusca vary from $\cdot 13$ to $\cdot 16 \mathrm{~mm}$. length, and $\cdot 05$ to $\cdot 06 \mathrm{~mm}$. breadth. Schewiakoff gives for $F$. leucas $\cdot 11$ to $\cdot 22 \mathrm{~mm}$. length, and $\cdot 05$ to $\cdot 1 \mathrm{~mm}$. breadth. The nucleus is spheroidal, and situated as in the marine form described by Calkins.

The body carries very fine close striæ on which are the cilia, of even length all over the body. The cilia appear to rise each from a very small papilla, which papillæ form the striæ, and Schewiakoff states that this is the case. Minchin, however (Introduction to Study of Protozoa, p. 442), states that in Frontonia each cilium arises from the centre of a small depressed area of the surface.

There are many trichocysts in Frontonia fusca, oblong in shape with rounded corners. In Frontonia leucas, Schewiakoff shows them as lenticular. The exploded trichocysts of $F$. fusca are threads about $.016 \mathrm{~mm}$. long. Schewiakoff figures those of $F$. leucas with two hooks at the end; but Minchin's illustration, p. 447, after Schubert, shows them with clubbed ends.

Frontonia fusca is greyish in colour, with many food vacuoles and refringent granules. I have found it in Drake's Island Tank among algæ in March and April, but not in any great number. I had not seen it previous to 1922. It has been described by Quennerstedt (25) as Panophrys fusca, and by Fabre-Domergue (12) and Kent (18) as Plagiopyla fusca, but I have not had an opportunity of consulting these two authors.

The meganucleus is spherical or ovoid, and lies nearly in the centre of the body. There is one micronucleus. At division the meganucleus assumes a dumb-bell shape, and gradually separates into two portions ; and at the same time the micronucleus divides into two, so forming the mega- and micronuclei of the two new individuals.

I have seen one case of conjugation, but was unable to follow the details.

\section{ANCISTRUM MYTILI (Quenn.).}

This small ciliate was first described by Quennerstedt (25) under the name of Opalina mytili. Maupas (20), however, pointed out that Quennerstedt was mistaken in referring it to the genus Opalina, as it possesses a mouth; and food vacuoles are present in the endosarc. Quennerstedt failed to see the mouth, and denied its existence. He, however, did recognize the vacuoles containing food; but compared them with those observable in the Acineta, which, according to him, also have no mouth. Maupas points out that he is wrong again, inasmuch as Acineta have as many mouths as suctorial tentacles through which they ingest food. 
Maupas also criticized the accuracy of Quennerstedt's observations on the general anatomy of the ciliate, and described it himself under the name of Ancistrum mytili.

Ancistrum is found in abundance among the branchial filaments of the common mussel. Here it attaches itself, and doubtless feeds on the small particles of food, of which the cilia of the branchiæ cause a constant flow.

It appears that Ancistrum goes through all the stages of its life history among the branchiæ, and I have met with many stages of development in infected shells.

Ancistrum mytili is a small colourless ciliate, averaging $\cdot 06$ to $.08 \mathrm{~mm}$. in length, and about $\frac{1}{3}$ of the length in the broadest part. It does not appear to possess any contractility. The body is wider and thicker at the posterior than at the anterior pole, and is bent on itself, so that in profile it resembles an arc, of which the dorsal surface is convex, and the ventral flat and concave. (It should be noted that Maupas, in his description, places the mouth at the posterior extremity, and regards the wider extremity where are the cilia by which fixation is effected as the anterior. I see no reason for this change in the usual convention, and call the end where the mouth is situated the anterior.) In consequence of the curvature it is difficult to get an accurate representation of the body parts. The figures are drawn from slightly flattened specimens, and thus cannot represent exactly the arrangement of the cilia. The perisarc is finely striated, showing the lines of cilia, and on the dorsal surface are two parallel ridges (Fig. 25) (dr) running from the anterior margin, which is obliquely truncated from right to left and dying out posteriorly. The cytoplasm contains a few food vacuoles, and a few refringent granules. Generally speaking, it is rather clear. The cilia are long, and follow the striæ of the integument. Those on the side of the mouth (that is the left side when the animal is lying in a ventral view) are longer than the others, and when at rest, in the lower $\frac{1}{3}$ of the body, lie pressed to the side, so giving the appearance of a fringed margin (Fig. 26) (fm). On the posterior part of the ventral surface (Fig. 26) (ct) there is a large patch of short, thick-set cilia, which, when the animal is at rest, stand out at right angles to the surface, and appear to form points of attachment. When the animal is viewed dorsally (Fig. 25) (ct) the ends of these cilia show up in optical section as black points on the coverslip. While the animal is at rest the cilia around the posterior margin may often be seen in rapid motion, giving the idea of rotation. Meanwhile the cilia on the body lie wrapped round the animal. Ancistrum moves with a rapid, jerky motion, revolving round its axis. It proceeds in a hurry for a short distance, comes to rest, and again starts off on an erratic course. 
In a ventral view, the cytostome (Fig. 26) (cys) may be seen as a small oval fossa in the left-hand corner, which I observe is extended into a longish narrow cytopharynx (cyp), which varies in visibility. Sometimes it is not to be seen at all. Maupas says he thinks he sometimes saw it. Maupas then proceeds to describe how the mouth is provided exteriorly with a large vibratile membrane, of which it is difficult to observe the arrangement and points of attachment; but without being perfectly

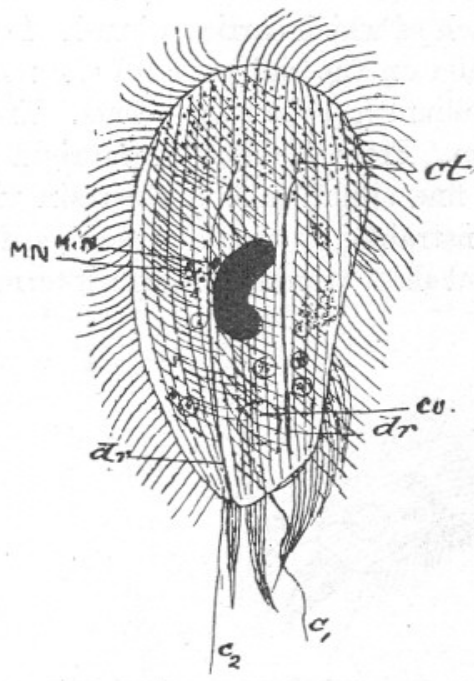

FIG. 25.

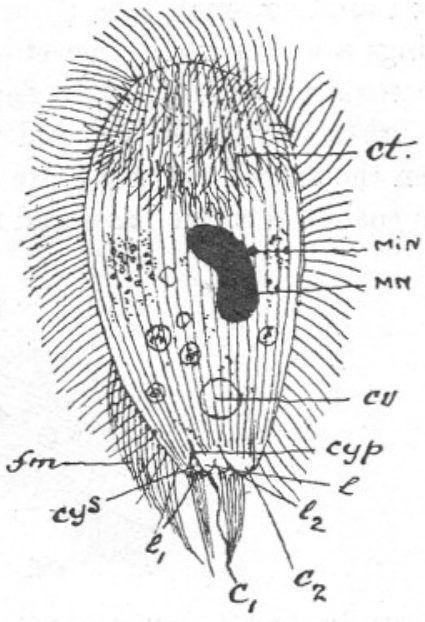

Frg. 26.

FIG. 25.-Ancistrum mytili. Dorsal view. $\times 630$. Camera lucida. MN., meganucleus; MiN., micronucleus; ct., cilia which probably form points of attachment in optical section; $d r$., dorsal ridges; $c_{1}$, flagellum-like cilium ; $c_{2}$, long cilium; $c v$., contractile vacuole.

Fig. 26.-Ancistrum mytili. Ventral view. $\times 630$. Camera lucida. MN., meganucleus ; MiN., micronucleus ; cys., cytostome ; cyp., cytopharynx ; fm., fringed margin; $\left(l_{1}\right)$, small lobes carrying bunch of cilia (these do not appear clearly in the figure as the cytostome interferes with the view); $l$, lobe to right of cytostome bearing flagellum-like cilium ; $\left(l_{2}\right)$, lobe bearing long eilium ; ct., cilia which probably form points of attachment; $c v$., contractile vacuole.

certain he thinks he may compare it to the vibratile membrane of Pleuronema chrysalis. He also describes how particles of food are swept by the eddies of the cilia into this net-like membrane, which then contrácts, and draws them into the mouth. The membrane is in constant change and motion, and very contractile. It is this membrane, he says, that Quennerstedt has taken for a bundle of entangled cilia.

I have examined numbers of Ancistrum, and have never been able to detect any sign of a vibratile membrane. Under low magnification, the 
bundle of cilia (fm) on the left anterior margin give an outline, somewhat resembling the outline of the membrane in Maupas' figure. As the animal has frequent periods of rest, it is easily viewed under an immersion lens, and all the circumoral appearances are easily resolved into cilia. As the body in the natural state is curved, these bunches of cilia project vertically upwards, and their ends appear as a semi-ring of dots around the mouth, and it is difficult to decide exactly how they arise. When the animal, however, is slightly compressed as in the figure, they are seen to arise from two small lobes $\left(l_{1}\right)$, each of which carries a brush of cilia. From another small lobe (l) or papilla on the right side of the mouth springs a longer and rather stouter cilium $\left(c_{1}\right)$ than the others. This is in constant vibration, like a flagellum. From the lobe on the right side $\left(l_{2}\right)$ arises another longer and very fine cilium $\left(c_{2}\right)$. In certain views when the animal is lying quite unconstrained, it would appear as if the cilia coalesced at the bases and formed short trunks from which terminal

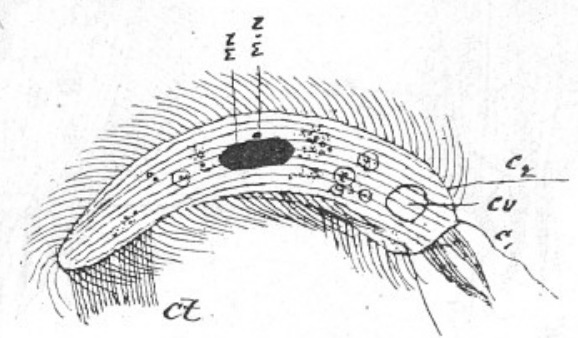

FIG. 27.-Ancistrum mytili, side view. $\times 630$. Camera lucida. ct., cilia forming points of attachment; $c_{1}$, flagellum-like cilium; $c_{2}$, long cilium; $M N$., meganucleus ; MiN., micronucleus; $c v$., contractile vacuole.

cilia spring; but I am not quite certain of this, as it is not evident when the bunches of cilia are straightened out by compression. Also the ends of the two bunches cross one another when quite unconstrained. When a side view of the animal is obtained (Fig. 27), these bunches of cilia are seen to project straight forward, and rest as do the posterior cilia on the branchial filament; but I have so far been unable to form any idea of how they function, or whether they play any part at all in conveying food to the mouth.

Quennerstedt was, I believe, perfectly correct in describing what he saw as a bunch of cilia, though he only saw the row on the left margin.

The contractile vacuole is situated near the mouth, but I cannot say, with Maupas, whether it is attached to the dorsal body wall. It is generally single, but I have occasionally observed two or three smaller contractile vacuoles. I have seen it functioning, which it does slowly, and there is no rhythm. I have not observed the anus, if there be any. The nucleus is median or slightly towards the upper half of the body. It is 
sometimes as described by Maupas an "oblong bent into an arc"; but as in the case of many other ciliates, its shape is variable. Sometimes it appears as a straight band, sometimes a row of spheres in a curve, sometimes a few spheres irregularly placed. There is a small spherical micronucleus (MiN) near the meganucleus (MN). The animal is very uncontractile, and easily stains with methyl green and acetic. The easiest way to examine it is to tease out a small piece of branchiæ, and press it down tight beneath a coverslip. The animal is so small that the thickness of the crushed branchiæ protects it, and it may be easily examined and if required fixed and stained in situ.

\section{Lionotus FASCIOLA (O.F.M.).}

When Wrzesniowski (28) found that Loxophyllum fasciola and Lox. folium were ciliated only on the ventral surface, he created the genus Lionotus, sometimes incorrectly written Litonotus, to include them, and two other species observed by him, and so separate them from other Loxophyllids (Wrzesniowski, 28, quoted by Maupas, 20). However, as Maupas points out (20, p. 507), Wrzesniowski should have considered whether a naked dorsal surface is not characteristic of all Loxophyllids, and has himself shown it to be the case with Lox. meleagris, Lox. rostratum, Lox. lamella, and three other species. Maupas, therefore, retains the generic name, Loxophyllum, and describes as a new species Loxophyllum duplostriatum, which apparently only differs from the ordinary form in having a double striation on the dorsal surface.

What is apparently the same animal has been described by various authors as follows :-

As Lionotus fasciola-Wrzesniowski, Schewiakoff, Calkins, Kent, Levander.

As Vibrio fasciola-O. F. Müller.

As Amphileptus fasciola-Ehrenberg, Dujardin, Eichwald, Lachmann.

As Loxophyllum fasciola-Claparède and Lachmann, Andrassowna.

As Loxophyllum duplostriatum-Maupas, Rees, Andrassowna, Gourret. and Rœeser.

As Litonotus trichooystus - Stokes.

The titles of the different papers will be found in the Bibliography at the commencement of No. XIII, Ciliata. Nordisches Plankton (16).

The descriptions of the general forms do not vary much. At Plymouth the ciliate is fairly common, and is often found in numbers in the film on the top of dredgings. Isolated individuals are not often met with. 
In shape it is slightly sigmoid. The ventral surface is flat and ciliated, the dorsal surface naked, and slightly arched. The body tapers gradually to the anterior end, where it has a slight dorsal turn; but there is no hooked rostrum, as in Lox. rostratum, nor any hyaline margin or caudal region. The body ends posteriorly in a rounded point (Fig. 28). With the above exceptions it resembles Lox. rostratum. The neck or pro-

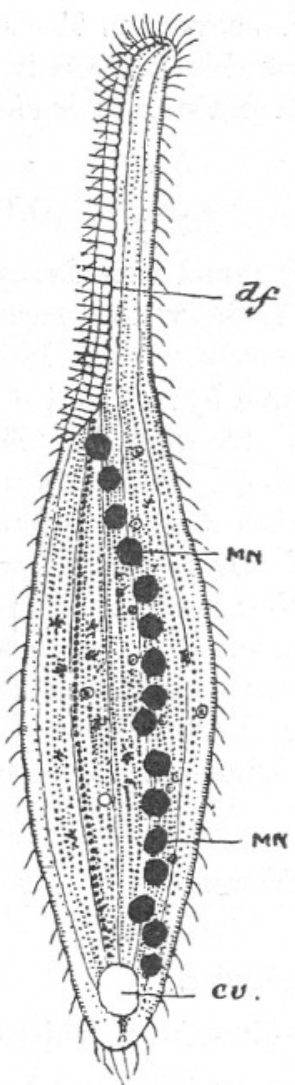

FIg. 28.-Lionotus fasciola. Dorsal view. df., dorsal furrow with stout cilia; $M N$., meganuclear elements; $c v$., contractile vacuole.

boscis forms about half the length of the whole animal when the animal is at rest, but longer when swimming; in fact, the neck portion is much more elastic and contractile than the rest of the body. When swimming the total length of the Plymouth.form varies from $\cdot 3$ to $\cdot 45 \mathrm{~mm}$., and the average greatest breadth $\cdot 045 \mathrm{~mm}$. Calkins gives the length as $\cdot 4$ to $\cdot 6$ mm., Maupas, $\cdot 3 \mathrm{~mm}$., Schewiakoff (for middle-sized animals), .08 to $.1 \mathrm{~mm}$. length, and $\cdot 017$ to $.02 \mathrm{~mm}$. breadth. 
A furrow runs the whole length of the left margin of the proboscis (the animal lying with the dorsal surface uppermost). Within this furrow lies the mouth opening. Schewiakoff says this consists of a long slit, and Calkins alludes to the "elongate mouth." I was unable to observe accurately how the mouth lies within the furrow. Maupas says that it lies on the left margin of the ventral face at the base of the neck or proboscis, and that it is completely closed and invisible ordinarily; and only to be detected when the animal swallows its prey. On the dorsal margin of the furrow there is a row of rather longer and slightly stouter cilia, which are, according to Maupas, slightly curved at the extremity, and were compared by Dujardin to a "mane" (erinière). It appears to me that in the Plymouth specimens they are certainly longer, and not so fine as the ventral cilia, although Maupas says that they do not differ from the latter. But they are by no means so marked or active as peristomial cilia generally are ; for example, the peristomial cilia of Spirostomum. The ventral cilia, according to Schewiakoff, rise from papillæ lying in seven or eight furrows. I have in Plymouth specimens counted ten rows of ventral cilia, but cannot decide whether the lines on which the cilia stand are furrows, or thickenings of the pellicle. Schewiakoff admits that they are only visible in starved specimens.

In the dorsal surface, which is without cilia, are four to five exceedingly fine striations. I cannot determine whether they are furrows or thickenings of the pellicle. Maupas describes a variety with five or six dorsal striations, and he describes and figures their appearance under very high magnification. On this character he founds a new species, Loxophyllum duplostriatum, which, in other respects, closely resembles Lionotus fasciola.

Schewiakoff observed the anus at the posterior end of the ventral margin of the body, and above it the contractile vacuole, which discharges on the dorsal surface. I have not seen the anus. There is a large vacuole generally visible at the posterior end, but 1 have not seen it function. Calkins says that the contractile vacuole is double or multiple at the posterior end.

The meganucleus, according to Schewiakoff, consists of two oval masses, connected by fine strands, which are only visible when the nucleus is isolated from the animal, and probably are extensions of the nuclear membrane. There is a small micronucleus.

Calkins describes the macronucleus as double, both parts spherical, but not connected as Schewiakoff contends.

Maupas says that the macronucleus consists of two nearly oval portions placed near one another in the line of the body axis; but that it is not uncommon to find four or five bodies differently placed as regards one another, and at a time when the animals give no sign of preparing 
for division. The nucleolus he states to be a small single or double sphere, but in some cases it was absent. I have not found the micronucleus in any specimen.

In none of the animals examined during the months of January, February and March did I find the double macronucleus. In one individual there were three large spherical masses. In others a number of smaller spheres, from twelve to seventeen, arranged in the long axis of the body, as shown in the figure. This may be compared with the case of Spirostomum lanceolatum. I have never seen Lionotus fasciola dividing or conjugating.

Calkins states that in conjugation a large form unites with a smaller one, the mouth parts being connected, and gives a figure.

Schewiakoff says that the body is colourless.

Calkins, that it is frequently brown or light yellow in colour. The Plymouth variety is light yellow, with darker granulations, and larger food particles.

Schewiakoff describes the habits, feeding, etc., of the animal in considerable detail.

Dysteria armata (Huxley).

Huxley (17) ; Entz (10); Kent (18).

This ciliate was first noticed by Mr. Dyster, of Tenby, on algæ coating the shells of Patella and Littorina, and brought to the notice of Professor Huxley, who was the first to describe it, and named the genus of which it forms the type, after his friend. Huxley pointed out that Dysteria closely resembles Euplotos monostyla, and Chlamydodon mnemosyne of Ehrenberg in structure; but P. Gosse (Journal Microscop. Science, 1857, p. 138) expressed the opinion that the structure of Dysteria was too complicated for an Infusorian, and that its true position was probably nearer to Monocerca and Mastigocerca among the Rotifera; at the same time suggesting that Dysteria might be an annectant form between the Rotifera and Ciliate Infusoria.

Huxley, however, pointed out that an animal taking solid nutriment, but without an alimentary canal, possessing a contractile vacuole and locomotory cilia, and reproducing by transverse fission, could hardly belong to any but the class Infusoria; and further, that the possession of a sort of shell or lorica, a submarginal ciliated groove round a large part of the body margin, and the inequality of the two lateral halves of the body, clearly point to the nearness of the animal to Ehrenberg's Euplota. In fact, were it not for the amethystine spot, and the peculiar oral apparatus, Huxley would have been disposed to regard Euplotes macrostyla and Dysteria armata as identical.

In spite of certain possible analogies between the manducatory appara- 
tus of some Rotifera and the "apparatus" of Dysteria, Huxley saw no grounds for regarding the latter as an annectant form between the groups.

The shape is ovoid. Length, $\cdot 08$ to $.125 \mathrm{~mm}$.; breadth, .05 to $.06 \mathrm{~mm}$. Huxley has: length, $\frac{1}{350}$ to $\frac{1}{250}$ inch, and breadth, $\frac{1}{40} 0$ to $\frac{1}{450}$ inch.

The body is divided by grooves into two unequal parts (Fig. 29). The upper or dorsal groove (dg) is wider and shallower than the ventral

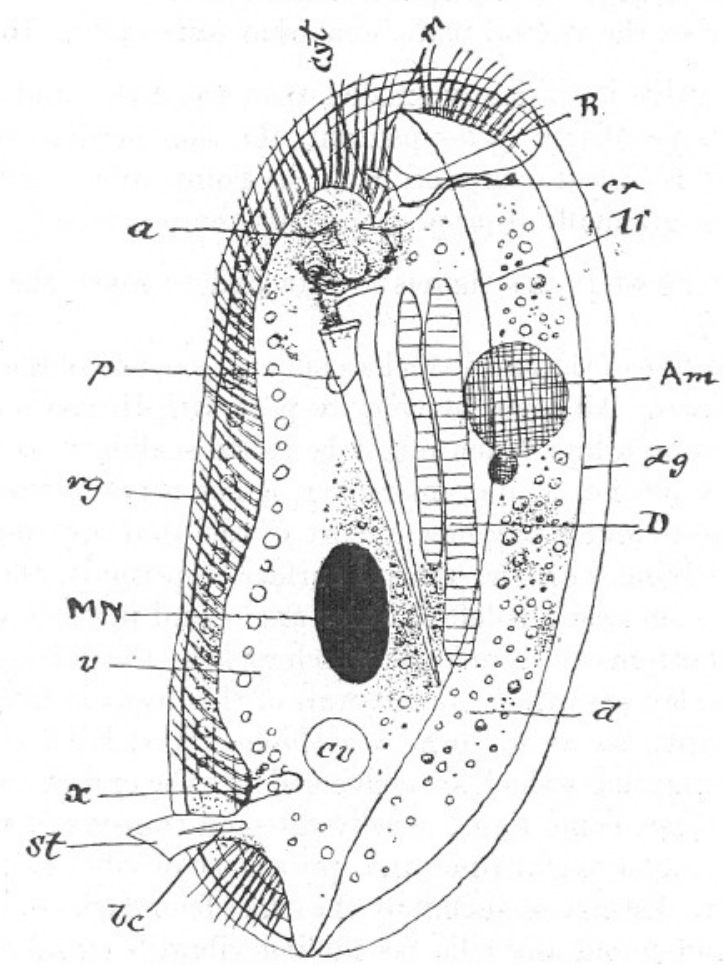

FrG. 29.-Dysteria armata. Ventral view. cyt., cytostome; m., obtuse ending of ridge ; $c r$., curved rod at bottom of oral fossa ; $R$., rod-like organ ; lr., longitudinal ridge; $A m$., amethystine spot; $D$., ingested diatoms ; $d$., dorsal area of ventral surface; $v$. , ventral area of ventral surface; st., style; $b c$. , blind canal; $x$. , sac-like body, Entz's "Safträume"; $M N$., meganucleus ; p., posterior mass of "apparatus "; $a$. , anterior mass of "apparatus"; $c v$. , contractile vacuole; $d g$., dorsal groove ; $v g$. , ventral groove.

(vg), which is deep and narrow. Anteriorly the dorsal and ventral grooves run into one another, but posteriorly unite for a short space. The upper dorsal or right surface is convex, and overlaps the ventral on all sides. The lower ventral or left is slightly concave, and is divided by a ridge (lr) into a larger ventral (v) and smaller dorsal (d) area. This ridge ends anteriorly in an obtuse point (m), and pos- 
teriorly forms one side of a triangular termination, which is sometimes pointed and sometimes more obtuse. The upper and lower surfaces are thinned out, and when viewed laterally the animal bears a resemblance to a bivalve shell. The surfaces are covered by a very clear hyaline pellicle, of sufficient toughness to allow of the protoplasmic body contents being extruded under pressure, leaving the pellicle and the interior pharyngeal arrangements undisturbed.

Entz describes the ventral plate somewhat differently. He says :-

"The left valve is evidently smaller than the right, and its anterior free margin is peculiarly scallopped out, the thin margins of the inner curves are often turned over, and from the points arise curved wrinkles or folds which gradually disappear towards the posterior."

A copy of one of Entz's figures is attached to make the description clear (Fig. 30).

This description of the left plate does not apply to any of the individuals I have examined. All agree in every respect with Huxley's description. In optical section a line which might be called scalloped, is to be seen ; but the angles are not acute ; moreover, it lies between the dorsal and ventral surfaces, and represents a part of the oral apparatus. When the animal is lying with the ventral surface uppermost, the cytostome (cyt) may be seen near the left anterior angle, and just below the ridge. It lies at the bottom of a deep fossa, which replaces the dorsal and ventral grooves. Huxley says that the left wall of this fossa is thickened, and projects inwards, so as to form a cushion-shaped lobe, clothed with remarkably long cilia - which are continued into the oral aperture itselfthe posterior ones being large, usually directed transversely to the axis of the body, and having at times the appearance of vibratile membranes. It is difficult to distinguish definitely the exact boundaries of the cushion, and I have not found any cilia resembling vibratile membranes.

There is, however, in the oral fossa lying below the ventral cilia, a rodlike organ (r) which beats intermittently, but not rhythmically with the other cilia. Huxley has drawn this in his figure, but has not alluded to it in the description. The bottom of the oral fossa is, says Huxley, strengthened by a curious curved rod (cr), terminating in a bifid tooth superiorly, and lost inferiorly in the wall of the fossa. This rod appears to be a thickening of the margin, and is always apparent, forming part of the scalloped line alluded to above. I cannot determine the exact shape or position of the bifid head. On the ventral side of the mouth, and extending through about two-thirds of the body, is an arrangement of hard parts, which Huxley calls the "apparatus." It consists of iwo portions, an anterior somewhat rounded mass (a) and an elongated, styliform, posterior portion (p) (Figs. 29, 31). The appearance of these 
two parts in optical section does not vary, even after the body protoplasm has been expelled from the pellicle by pressure; but it is difficult to determine the structure of the anterior mass. I cannot follow Huxley's description in every detail, but as I have no alternative to suggest, will quote his own words and reproduce his drawing in Fig. 31 :-

"It is very difficult to assure oneself of the precise structure of the anterior portion. It would seem to be a deep ring composed of three

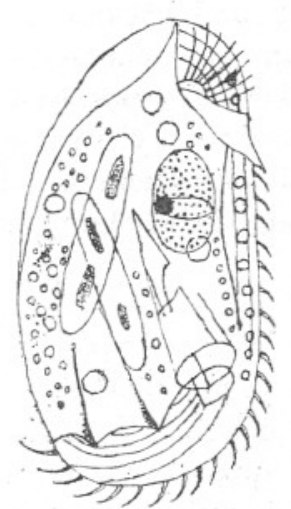

FIG. 30 .

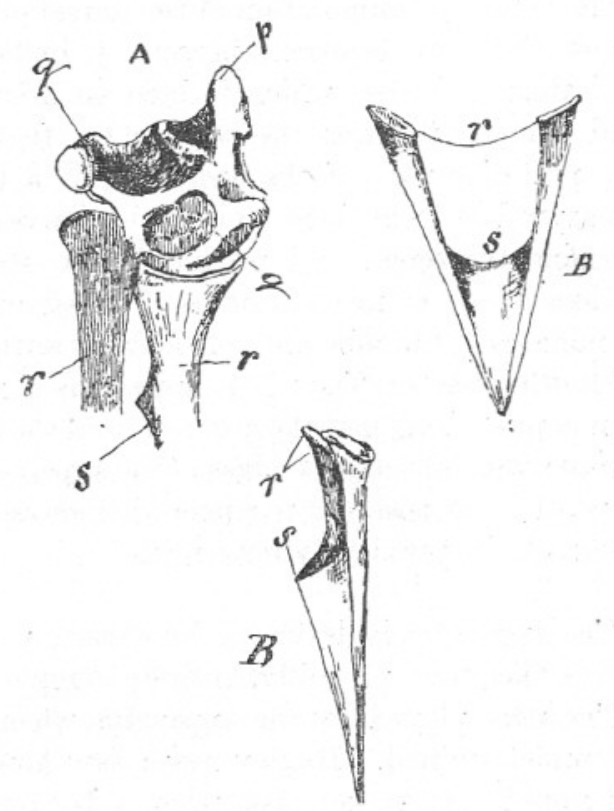

Fig. 31 .

FIG. 30.-Dysteria armata. Ventral view after Entz.

Frg. 31.-Dysteria armata. Enlarged drawing of "Apparatus" (after Huxley). A., anterior portion; $q q$. , superolateral portions; $p$., inferior azygos portion; $B B$. , two views of styloid portion; s., apparent downward process, which is really membrane connecting two styles; $r$., nail-like heads of styles.

pieces-two supero-lateral, and mutually corresponding $(q)$ united with a third, inferior, azygous portion (p). The latter is somewhat triangular, with a broad base, and rounded obtuse apex; the latter being directed forwards and immediately underlying the oral aperture, while the former is turned backwards and unites with the two supero-lateral pieces. Each of these is concave internally, and convex externally, so as to form a segment of a circle, and present a clear median space, the optical expression of either a perforation or of a much thinned spot. The anterior edge of each supero-lateral piece is nearly straight, but the posterior 
is convex, and it is by this edge that it articulates with or is opposed to the anterior extremity of the posterior division of the apparatus. Viewed laterally this posterior portion appears to consist of two styles, which are somewhat like nails in shape; their anterior extremities being truncated, so as to present a sort of nail head, while the posterior extremity seems to take to a fine point. Rather in front of the middle of its inferior edge each style seems to give off a short process downwards (S), and this process is in botanical language decurrent upon the style. Careful examination of the dorsal or ventral aspect of these parts shows that the decurrent process is, in fact, only the expression of a delicate membrane, which is bent so as to have a ventral convexity, and connects together the two styles. It might be said, therefore, that the posterior part of the apparatus is a triangular membrane, deeply excavated in front, bent so as to be convex downwards, and having its margins thickened and produced into styliform enlargements. This. curious piece of mechanism is directed upwards and backwards, and terminates in the substance of the body without any apparent connection with other parts. The whole apparatus is movable The posterior portion is pushed against the anterior, and the heads of the styles come into contact with the convex edges of the supero-lateral pieces, and push them forwards ; the posterior portion is then retracted, and the whole apparatus returns to its previous arrangement."

The apparatus is destroyed by caustic potash, but not by acetic acid and is therefore, probably, entirely composed of animal matter.

The part played by the apparatus when the animal is feeding is as yet undetermined. Huxley never saw how the apparatus functioned; but noted that in one case, when a Dysteria had swallowed a piece of Oscillatoria, so long that one end was projecting from the mouth, the movements of the "apparatus" took place as many times as twenty to. the minute.

Mr. Dyster stated that the frond of Oscillatoria was "swum upon" rather than seized, ingestion being accomplished by a smooth gliding. motion, apparently without displacement of the styles, but that when the act was completed the styles gave a kind of snap and moved slightly forwards. I have myself seen the animal apparently gliding on the fronds of the algæ, while feeding, and others have told me that they have seen the same. As soon, however, as the animal is arranged for observation under a sufficiently high power to observe the action of the apparatus. accurately, the Dysteria is put off his feed.

As the fronds of algæ are cut off in nearly equal lengths, and lie parallel to the dorsal margin, it may be conjectured that the "nails " and membrane form a kind of channel by which the alga is guided towards the 
posterior end of the body, and that the nail heads may play some part in cutting or breaking off the frond, at the required length.

Mr. Dyster thought that the Oscillatoria passed through the anterior ring-like portion of the apparatus. Huxley had not seen the animal feed, but on structural grounds thought that the food would pass above the anterior ring.

Entz (10) does not agree with Huxley's interpretation of the " anterior somewhat rounded mass," and writes as follows :-

"Above this dagger-shaped skeletal rod, a complicated rigid ring was distinguished by Huxley, composed of two paired and one unpaired skeletal parts, and not unlike the larynx of a mammal. I must confess that I could not convince myself of the presence of this ring. According to my observations the portion of the gullet anterior to the dagger-like skeletal piece is not rigid at all, but forms a tube of thin cuticle, which changes its outline according as it rolls in or out. In the unrolled state the anterior part of the pharynx resembles a loosely rolled paper funnel forming a wide channel with a circular gaping mouth opening, which the dagger-shaped skeletal piece serves to keep in place, being as it were the tube of the funnel. In the rolled-up state this part of the pharynx appears as a very inconspicuous tube closely rolled round the daggershaped piece, so that one cannot make out how the rather large pieces of Oscillaria that serve for food manage to get through it."

Whatever may be the true interpretation, Entz's figure does not represent the appearance of the apparatus as I have seen it, and as he himself admits it will not account for the passage of the fronds of algæ, or the position they assume dorsally and parallel to the apparatus.

Huxley notes one contractile vacuole a little behind the middle of the body, and my observations agree. It is generally posterior, and functions regularly. Entz states that he has constantly seen four, all in the left valve; two in the neighbourhood of the ventral margin, and the other two in the ventral margin. I have seen other vacuoles than the posterior one with the appearance of contractile vacuoles, but not functioning. Near the contractile vacuole, close to the style there is a smaller saclike oval body (x), which does not appear to contract. Huxley describes it as having the long axis $\left(\frac{1}{5000}\right.$ inch) directed upwards, and with a small central cavity. Entz also notices the presence of this vesicle under the name of "Safträume." I have not found this vesicle in all specimens examined, and am doubtful whether it is a persistent organ.

The Style (Griffel) is a scimitar-shaped organ (Huxley compares it to a boot, and Entz to a penknife blade), lying in the deep part of the ventral groove at the posterior end. Huxley locates it at about $\frac{1}{5}$ of the whole length from the posterior extremity. It contains a blind canal. It is 
capable of considerable play in the horizontal plane between the valves, and a splaying outwards of the dorsal valve admits of a certain amount of vertical motion.

Huxley says that the toe (he is comparing it to a boot) appears to be viscid, and so readily adherent to any foreign object. The animal certainly appears to use it as a pivot, about which the whole body turns. While so resting nutriment is swept towards the mouth by the neighbouring cilia. Behind the Style is a bundle of long, stout cilia-Huxley alludes to one particularly large stout one among these-but this I cannot. detect. Similar cilia extend along the right margin of the ventral plate (viewed dorsally), and extend into the oral fossa. There is another tuft of similar cilia at the anterior end, just to the left of the ventral ridge. On the clear ventral margin, where the dorsal valve overlaps the ventral, rows of very fine striæ may be observed. These carry cilia, much finer and closely set than the row above described. Huxley does not mention them. Entz does, and shows them in his figure.

On the left of the pharynx in the anterior part of the body is a large rose-coloured sphere, apparently containing a clear homogeneous fluid. This Huxley calls the "amethystine body." It is situated in the convex part of the body, and generally a small similar sphere is connected with it. I have seen cases in which two amethystine bodies were present : one, as described above, and the other in the middle of the body. The object of these is not, as far as I am aware, determined. Entz suggests that they may be reservoirs for the colouring matter resulting from the algæ broken down in digestion. I have not observed that they discharge their contents.

The protoplasm of the left valve contains many fine granules, mingled with larger refringent globules, and along the ventral margin of the right valve there is a row of rather large refringent spheres whose position is constant.

Nucleus. Huxley did not find the nucleus.

Entz describes it as a clear oval body lying just below the middle of the body, and near the nail or dagger-like apparatus. It is often found divided by a nearly median plane, transverse to the major axis. I have seen it in this stage, and in others, when it formed a very irregularly shaped mass, or masses. In the ovoid form the anterior portion stains more deeply than the posterior. In the living animal the meganucleus is observable as a clear ovoid space.

Entz observed the micronucleus. I have failed to do so. Division is by transverse fission, and Huxley notes that the apparatus disappears and is reproduced during the process. Only rudiments of it were noticeable in each half of the dividing animal. My observations are similar.

Dysteria is common among algæ in Drake's Island Tank during March and April. 
Dysteria is evidently a highly specialized ciliate and would repay further investigation, particularly as to the structure and function of the apparatus. The hardness of these parts makes it probable that something might be done by the recent methods of micro-dissection.

Egyria oliva (Clap. et Lach).

Claparède and Lachmann (5) ; Gruber (14) ; Rees ; Entz (10) ; Kent (18).

This ciliate was placed by Claparède and Lachmann among the Dysteriidæ; but Entz points out that both in general form and in the shape of the cytopharynx it much more closely resembles the Chlamydodontidæ, and especially Trichopus dysteria. He, therefore, included it in that family.

It is not very common in Drake's Island Tank, and I have found only solitary individuals, and this also is the experience of Claparède and Lachmann and Entz.

Entz has described Eygria oliva very fully, and with excellent figures. Claparède and Lachmann and Kent describe shortly, and their figures are unsatisfactory; Kent's is only a reproduction of Claparède and Lachmann's.

This genus possesses the singular character of being able by contraction to bring the dorsal and ventral body surfaces together like the valves of a mussel-shell with, at the same time, torsion of the body round its long axis.

In consequence of this the appearance of the animal varies, and Entz describes it under three forms: the Flat, the Oliva, and the "Rolled up."

The Flat and the Oliva are the only two forms I have seen; but the "Rolled up" is only a further extension of the Oliva, combined with torsion.

I follow Entz description, which applies equally to Plymouth specimens.

In general form the "Flat" variety may be compared to a mussel shell with unequal valves (Fig. 32), the ventral side of the ciliate representing the left, and the dorsal side the right valve of the shell. The left body margin represents the hinge edge, and the right body margin the outer edge of the mussel.

Starting from the posterior end the right margin of the body describes a gentle curve forward and upward, and then bends to the left, and traces out the rounded and mobile frontal lobes. From this point the left body margin describes a very flat $\mathrm{S}$ curve, and joins in to form the smaller, rounded, posterior lobe. The ventral side is flat; but the dorsal, particularly the posterior portion, slightly arched. The ventral surface is finely 
striated. The striæ follow pretty closely the curves of the body margin, and carry cilia, which are fairly long and thick, and almost bristle-like, especially on the frontal lobe. The dorsal surface is smooth. In the right half of the ventral surface the ciliated striæ run straight towards the terminal point of the posterior lobe, but in the right half form a kind of whorl around the style.

The style is a singular conical or dagger-shaped, very motile object, which, according to Entz, consists of a number of conical surfaces, one within another and closely pressed together, so as to form a solid conical mass. His idea is that the rows of cilia pressed together form lamellæ,

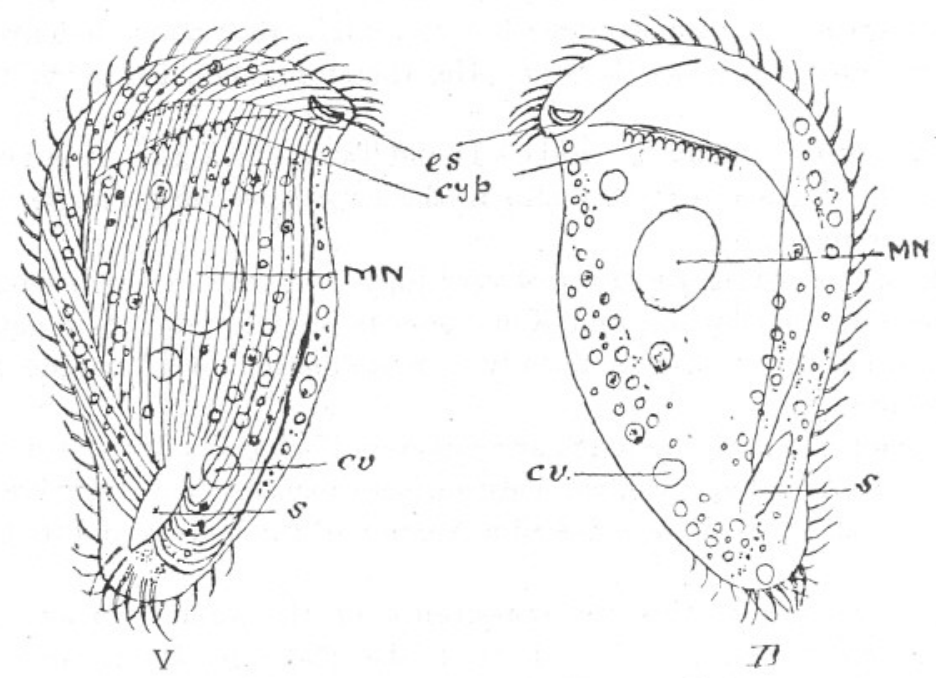

Frg. 32.-Egyria oliva. Flat form. D., dorsal; V., ventral view ; es., eye spot; cyp., cytopharynx ; MN., meganucleus ; $c v$., contractile vacuole ; s., style.

and then, coiled spirally together, form the conical style. Close below the style is a group of five or six very stout cilia.

The œsophagus or cytopharynx is a short, wide, flattened tube lying obliquely from right to left below the anterior lobe, and surrounded by broad short rods. As the anterior portion of Egyria is generally very transparent, it is easy to see these rods, under a high power, either from the ventral or dorsal surface.

Of the mouth, Entz writes :-

"In AEgria oliva the mouth does not open directly on the ventral surface as it appears to do, but between the lamellæ of the frontal lobes, similarly to Chlamydodon cyclops. The whole body of the flat form of AEgria oliva may be compared to an unequally valved mussel. The ventral face represents the left, and the dorsal the right valve; the left 
body margin the hinge border, and the right the lower margin of the mussel. The right body margin from the extremity of the frontal lobes to the mouth, and from the right angle of that further along the right margin, splits into a small zone, and carries food to the mouth; and in this channel there is always a water vortex (caused by cilia). The inner margin of this slit is finely striated, like the flat mantle of mussel valves. Dorsally viewed the entrance of the gaping slit may be seen at the point of the frontal lobe."

Entz description is not very clear, and I have not seen the split at the point of the frontal lobe. In fact, the frontal lobe in his figure has been given a twist, which appears unnatural. The ciliated small

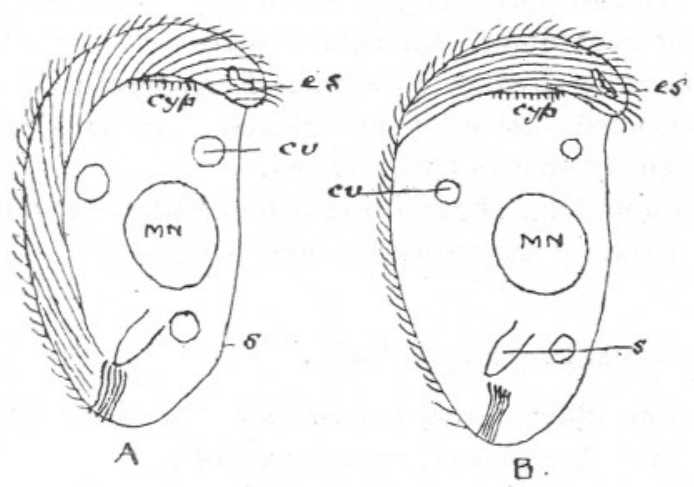

FIG. 33.

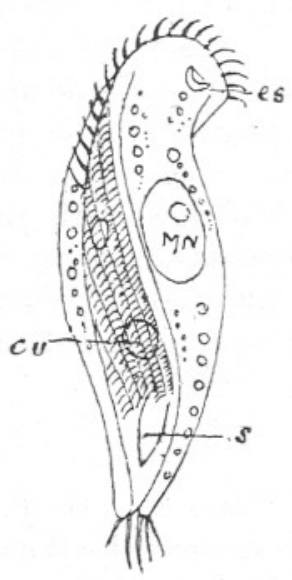

FIG. 34.

FIG. 33.-Agyria oliva. A., oliva form after Entz; B. oliva form with overlap parallel to transverse axis. Lettering as in Fig. 32.

Fig. 34.-Agyria oliva. " Rolled" form, after Entz. Lettering as in Figs, 32 and 33.

zone, and the water vortex, with the rods of the cytopharynx, are all easily seen.

I do not think that Entz three forms-Flat, Oliva (Fig. 33), and "Rolled up" (Fig. 34) - can be considered permanent forms. In the Oliva form he represents the doubling over of the ventral surface as occurring along the left margin and parallel to the longitudinal axis of the body - such bending accompanied by body torsion would produce the "Rolled up" form figured and described by him. But I have come across instances in which the doubling over occurred along the frontal line, and, therefore, at right angles to the longitudinal axis. Moreover, more than one-third of the dorsal surface was covered.

No torsion would be possible, or would produce Entz "Rolled-up" 
form. It appears to me, therefore, that the overlapping of the surfaces is a matter of circumstance, and may occur at either margin, accompanied or not by torsion of the body.

I have seen three contractile vacuoles-one at the posterior end, and the others in different parts of the body-and I saw all pulsating.

The meganucleus lies below the cytopharynx, a large round oval or circular mass. I did not notice the transverse division mentioned by Entz. Entz also states that he saw the micronucleus in living individuals.

Egyria is generally coloured by the various algæ on which it has been feeding; but the protoplasm of the body is singularly clear, and interferes very little with observation.

At the anterior end, at the point of the frontal lobe, there is a welldefined, dark-coloured, eye-like speck (Figs. 32 to 34). The colour appears to vary in different individuals. Entz states that it is a concaveconvex lens, with the concavity directed forwards. Kent regards it as homologous with the so-called "amethystine globule" in Huxley's Dysteria armata, or the pigment spot in Ophryoglena.

Although only $\cdot 08$ to $\cdot 14 \mathrm{~mm}$. long, Egyria is easy to detect on account of its shape and the eye-speck. It moves with a slow, irregular roll.

\section{LACRYMARIA OLOR (O.F.M.).}

Vibrio olor O. F. Muller (23); Trachelocerca olor Ehrenberg (9); Lacrymaria olor Bütschli (3); Lacrymaria olor Penard (24).

Very plentiful in Drake's Island Tank in March. The body (Fig. 35) is spindle-shaped, prolonged posteriorly into a narrow tail, which is very contractile, sometimes attaining a length equal to that of the body. The body itself is not, or very slightly, contractile; but the neck is enormously so, so that the whole length of the animal may reach 1.3 or even $1.5 \mathrm{~mm}$. The length is, therefore, extremely variable. On an average the length of the body, including the tail, ranges from $\cdot 11$ to $\cdot 16 \mathrm{~mm}$., the tail being rather less than half the body, and ordinarily the neck may be four to six times the length of the body and tail. Although the neck is so elastic the body always retains its spindle shape.

The animal is very transparent, and although there are many food vacuoles, the food must be very fine, as it hardly interferes with observation.

The body and neck are marked with spiral striæ, which become straight when the animal is at its maximum extension. Being so transparent it is possible to see the striæ on both sides, and receive the impression of cross striation, and thus the animal has been described as possessing longi- 
tudinal and transverse striæ. There are actually only single spirals, the angles varying according to the degree of extension. The cilia lie along the striæ.

Penard, in describing the fresh-water Lacrymaria olor, says that there are generally two contractile vacuoles, one of which is always posterior, the posterior being the important one, and always present. I have in the salt-water form seen two and three vacuoles, one posterior, and two in other parts of the body, but have never observed any pulsation.

The cytostome is terminal, and narrow, with a long, narrow cytopharynx, which is highly distensible. The exact shape of the terminal end of the neck in which the cytostome is situated is difficult to observe, because of the extreme narrowness of the neck, produced by extension and the restlessness of the animal. When contracted to the average

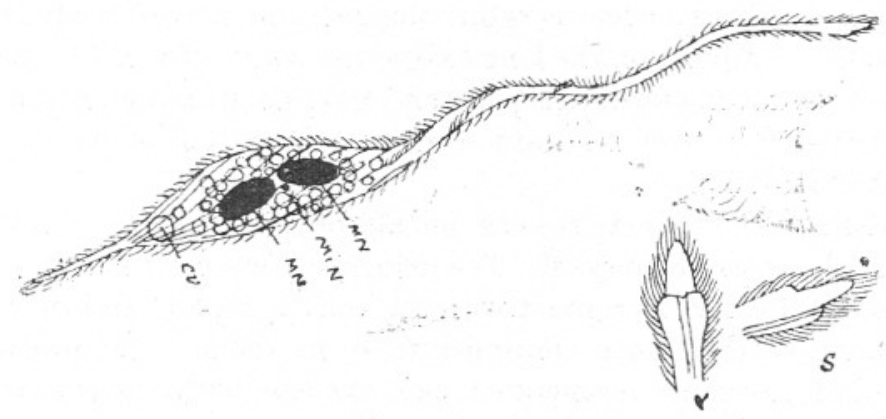

A

FIg. 35.-Lacrymaria olor. MN., meganucleus ; MiN., micronucleus ; $c v$. , contractile vacuole; $A$., mouth enlarged; v., ventral; s., side view.

length the neck appears to terminate in a kind of cone, surrounded at the base by a circlet of cilia. After very careful watching it appears to me that the neck, when the animal is at maximum extension, terminates in a long pointed lobe, with two short obtuse lobes at its base, and between these lobes lies the mouth. Behind the long lobe and slightly below its base is a smaller prominence, as shown in the drawing. The whole are surrounded by cilia, but I did not detect any definite ring of cilia. When the animal is more contracted, and the lobes are withdrawn, the appearance of a terminal ring is probably produced.

It appears to be the shape of the mouth which decides the difference between Trachelocerca and Lacrymaria. The "stopper-like" distal end of the neck when the animal is contracted more resembles the Lacrymaria type, while the oral lobes under greater extension suggest Trachelocerca; and Quennerstedt describes as Trachelocerca tenuicollis a form which resembles the Plymouth form. In his figure the mouth is not very 
definite. Penard's description of Lacrymaria olor so closely resembles that under reference, that I retain the genus Lacrymaria. The distinction between Lacrymaria and Trachelocerca, as fresh-water and marine forms, appears to me to be quite arbitrary.

There are trichocysts distributed irregularly through the body, and in the neighbourhood of the cytopharynx. These trichocysts discharge a filament sometimes $\cdot 01 \mathrm{~mm}$. in length.

The meganucleus generally appears as two oval masses lying near the centre of the body with the micronucleus between. Sometimes, however, the oval bodies are club, horseshoe, or dumb-bell-shaped, and at others both are fused into one large mass, which may be of any of the above forms. These arrangements no doubt depend on the stage of life of the animal, and are only true for that particular stage. The nucleus may be therefore represented conventionally by two oval masses.

Lacrymaria olor as a whole is rather sluggish, and moves slowly forward in the water, revolving on the long axis of the body. The neck, however, is very active, darting forward rapidly and extending, and again retracting.

It appears to be very resistant to the concentration of the sea-water in which it is living.

Any damage to the body is very quickly repaired. Very often the extended neck is seen to snap off. The detached portion then swims about alone, and if it comes in contact with the body is rapidly absorbed by it. The renovated whole then continues to swim about; and probably a new head and neck are regenerated, as is the case with Dileptus gigas.

Division is transverse, and Penard points out that it might easily be imagined to occur along a diagonal line, as the necks and tails of the two new division products increase before actual separation takes place, thus giving the idea that two animals are lying side by side.

Kent (p. 516) states that in company with an abnormal abundance of Trachelocerca olor, he found many forms resembling the Lacrymaria lagenula of Claparède and Lachmann. After careful watching he found that the Lagenula gradually developed a neck, and came in every respect to resemble $T$. olor.

Finally, he came to the conclusion that the short-necked Lagenula, like zooids, were the derivatives by transverse fission of a long-necked animalcule, and represented the hinder moiety of the division process. As far as I am aware this observation has not been repeated; but there does not seem any objection to its probability, as it would only imply that division was completed before the neck of the hinder moiety had commenced to develop to a marked extent.

Beyond the functioning of the contractile vacuoles I can note no difference between the marine form of this ciliate I have observed and the descriptions I have read of the fresh-water form. 


\section{LOXOPHYLLUM ROSTRATUM (Cohn).}

Described by Cohn (6) and figured, as a new species, compared with Plymouth examples, Cohn's Fig. 8 makes the rostrum too pronounced and acute, even when the animal is completely retracted. His Fig. 9 is a good representation of the animal when lying quiescent. But when swimming the neck is more extended, and can be elongated, so as to give

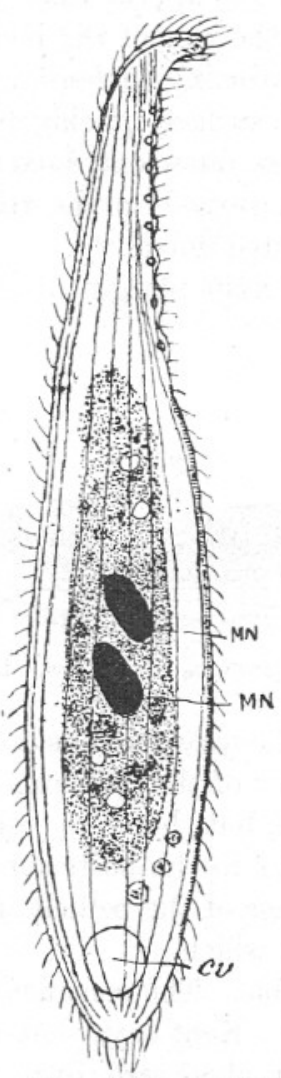

Frg. 36.-Loxophyllum rostratum. Dorsal view. MN., meganucleus; $c v$., contractile vacuole.

a total length of $\cdot 8 \mathrm{~mm}$. Cohn gives no measurements. Hamburger and Buddenbrock (16) gives the length as $\cdot 18 \mathrm{~mm}$. ; Kent (18), ${ }_{1 \frac{1}{4}}$ inch (about $\cdot 17 \mathrm{~mm}$.). I have measured a large number under ordinary conditions and find an average length of $\cdot 3 \mathrm{~mm}$. to $\cdot 4 \mathrm{~mm}$. The body is leaf-like (Figs. 36 and 37 ) and quite flat on the ciliated ventral surface, while the dorsal surface is convex, or may have one or two prominent curved humps. The degree of curvature depends on the amount of food present. 
The body is surrounded by a delicate hyaline lamina, the presence of which distinguishes Loxophyllum from Lionotus, which in other points it resembles. The body is prolonged anteriorly into a delicate tapering neck, which is possessed of great flexibility, and plays the principal part in the general elongation of the body. The neck terminates in an uncinate rostrum, on which the cilia are longer than those of the rest of the body, except a few at the posterior extremity, which, when the animal is extended, is pointed. It does not appear that the rostral termination is of any denser material than the rest of the body, but when the animal is under a coverslip and contorting violently, the rostral end frequently breaks off. The fractured surface quickly regenerates, and the animal continues swimming. When quiescent, Loxophyllum lies on the ventral surface, with the rostrum turned to the right. When swimming the rostrum is frequently elevated dorsally.

Below the rostrum the right margin of the neck has an undulating

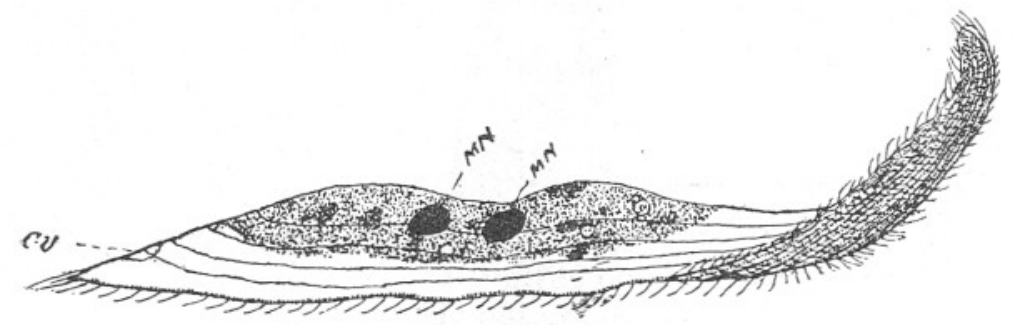

Fig. 37.-Loxophyllum rostratum. Side view. Lettering same as Fig. 36.

outline, and a row of trichocysts extends from this undulating margin near to the apical extremity of the rostrum.

There are no dorsal cilia, but there are eight extremely fine striations extending from the anterior to the posterior extremity. These may be either furrows or thickenings of the pellicle, forming small ridges. It is very difficult to determine which.

The meganucleus is double. The contractile vacuole is terminal, and I have seen it functioning. Kent says that there are one, two or three vacuoles; and Cohn that there are one, two, or more. There are numerous vacuoles containing food, etc., and these coalesce in varying degrees; but I have only seen one that can be called a true contractile vacuole, and that is the one at the posterior end.

The animal moves slowly, occasionally revolving on the long axis, and prying about with the rostrum. It is fairly common in Drake's Island Tank, and easy to recognize.

I have been unable to make out the mouth. Kent does not say anything about it. Cohn says that it is indistinct, and probably situated in a furrow. 


\section{BIBLIOGRAPHY.}

1. Bory de St. Vincent. 1824. Encyclop. Methodique Zoophytes.

2. Buddenbrock. 1920. Archiv. für Protistenkunde. Vol. 41, p. 346.

3. Bütschli, O. 1887-89. Broun's Klassen n. Ordn. Band. I.C.

4. Calkins, G. N. 1902. Marine Protozoa from Wood's Hole. Bull. of the U.S. Fish Commission. Vol. XXI, p. 446.

5. Claparède and Lachmann. 1858-61. Études sur les Infusoires et les Rhizopodes de Genève.

6. Cohn, F. 1866. Neue Infusorien im Seeaquarium. Zeitschr. für wissenschaft. Zool. Bd. 16.

7. Daday, E. 1886. Ein kleiner Beitrag. Zur Infusorien fauna des Golfes von Neapel. Mitt. d. Zool. Station. Bd. 6.

8. Dujardin, F. 1841. Histoire nat. d. Zoophytes Infusoires.

9. Ehrenberg, Chr. 1838. Die Infusorienstierchen als. volkommene Organismen. Leipzig.

10. Entz, G. 1884. Über die Infusorien des Golfes von Neapel. Mitt. d. Zool. Station. Neap. Bd. 5.

11. Engelmann. 1862. Zeitschr. f. wiss. Zool. XI, p. 379.

12. Fabre-Domergue, M. 1888. Recherches anatomiques et physiol. sur les Infusoriens ciliès. Ann. Sci. Nat. Zoologique. Bd. 5.

13. Fresenius. 1865. Die Infusorien des Seewasseraquariums. Zool. Garten. Frankfurt. Bd. 6.

14. Gruber, G. 1884. Die Protozoen des Hafens von Genoa. Nova acta. Acad. C.L.C.G. Bd. 46.

15. Gourret, P., et Roeser. 1886. Les Protozoaires du Vieux-Port de Marséille. Archiv. Zool. Exp. Bd. 4.

16. Hamburger und Buddenbrock. 1911. Nordische Ciliata. Nordisches Plankton, XIII. Kiel und Leipzig.

17. Huxley. 1857. Quart. Journ. Micr. Sci. Vol. 7.

18. Kent, W. S. 1880-82. A Manual of the Infusoria.

19. Levander, K. M. 1894. Beitr. z. Kenutnis einiger Ciliata. Acta pro Fauna et Flora fenn. Bd. 9. 
20. Maupas, E. 1883. Contributions à l'Étude morphologique et anatomique des Infusoires ciliés. Archiv. de Zool. Exp. Vol. 1. Second series.

21. Minchin, E. A. 1912. An Introduction to the study of the Protozoa.

22. Möbius, K. 1888. Bruchstücke einer Infusorienfauna der Kieler Bucht. Archiv. f. Naturgesch.

23. Müller, O. F. 1786. Animalcula Infusoria fluviatilia et marina. Hafniæ.

24. Penard, E. 1922. Études sur les Infusoires d'eau douce.

25. Quennerstedt, A. 1865. Bidragtil Sveriges Infusoria Fauna. I. Acta Universitatis Lundunensis. Bd. 2.

26. Stein. 1867. Der organismus der Infusoriensthiere. Abteilung II.

27. Schewiakoff, W. 1889. Beitr. z. Kentniss der Holotrichen Ciliaten. Bibliotheka Zoologica. H.S.

28. Wrzesniowsky. 1870. Beobachtungen über Infusorien ans der Umgebung von Warschau. Zeitschr. f. wiss. Zool. Bd. 20. 